J. Dairy Sci. 92:5769-5801

doi:10.3168/jds.2009-2431

(c) American Dairy Science Association, 2009.

\title{
Invited review: Body condition score and its association with dairy cow productivity, health, and welfare
}

\author{
J. R. Roche, ${ }^{1}{ }^{1}$ N. C. Friggens, † J. K. Kay, ${ }^{*}$ M. W. Fisher,‡ K. J. Stafford,§ and D. P. Berry\# \\ *DairyNZ Ltd., PO Box 3221, Hamilton, New Zealand \\ †UMR INRA-AgroParisTech Model Syst. Nutr. Rum., 16 rue Claude Bernard, 75231 Paris, France \\ ¥Kotare Bioethics, PO Box 2484, Stortford Lodge, Hastings 4153, New Zealand \\ §Institute of Veterinary Animal and Biomedical Sciences, Massey University, Palmerston North, New Zealand \\ \#Teagasc, Moorepark Dairy Production Research Centre, Fermoy, Co. Cork, Ireland
}

\begin{abstract}
The body condition score (BCS) of a dairy cow is an assessment of the proportion of body fat that it possesses, and it is recognized by animal scientists and producers as being an important factor in dairy cattle management. The scale used to measure BCS differs between countries, but low values always reflect emaciation and high values equate to obesity. The intercalving profile of BCS is a mirror image of the milk lactation profile. Cows lose condition for 50 to $100 \mathrm{~d}$ postcalving, because of homeorhetic changes that occur in the somatotropic axis and the sensitivity of peripheral tissues to insulin, and the upregulation of lipolytic pathways in adipose tissue. Management and feeding have little effect on early postcalving BCS loss (wk 1 to 4 postcalving) until the natural period of insulin resistance has passed and the somatotropic axis has recoupled. There is evidence, however, that management and diet can influence the timing of recoupling of the somatotropic axis and the sensitivity of peripheral tissues to insulin, and gene expression differences in adipose tissue $30 \mathrm{~d}$ in milk confirm an effect of energy intake on lipogenic enzymes. The BCS in which a cow calves, nadir BCS, and the amount of BCS she loses postcalving are associated with milk production, reproduction, and health. Body condition score may also be a valid indicator of animal welfare, but further research is required to determine the effect of BCS and BCS change on how a cow "feels." Although the actual strength of the association may vary, there is relative consistency in the associations among calving and nadir BCS, and BCS change on milk production, postpartum anestrous, the likelihood of a successful pregnancy and days open, the risk of uterine infection, and the risk of metabolic disorders. For many production and health variables, the associa-
\end{abstract}

Received May 29, 2009.

Accepted August 31, 2009.

${ }^{1}$ Corresponding author: john.roche@dairynz.co.nz tion with BCS is nonlinear, with an optimum calving BCS of 3.0 to 3.25 (5-point scale); lower calving BCS is associated with reduced production and reproduction, whereas calving $\mathrm{BCS} \geq 3.5$ (5-point scale) is associated with a reduction in early lactation dry matter intake and milk production and an increased risk of metabolic disorders. Ongoing research into the automation of body condition scoring suggests that it is a likely candidate to be incorporated into decision support systems in the near future to aid producers in making operational and tactical decisions.

Key words: body condition score, health and welfare, reproduction, review

\section{INTRODUCTION}

Adipose tissue reserves are stringently maintained by peripherally and centrally produced hormones (Roche et al., 2008), in accordance with the "lipostatic" theory (Kennedy, 1953); the provision of nutrients for the neonate mammal, however, is facilitated by lipolysis and muscle catabolism for a period postpartum. Dairy cows exhibit this mammalian tendency to nurture the neonate from tissue stores (Bauman and Currie, 1980), losing "condition" for approximately 40 to $100 \mathrm{~d}$ after calving (Koenen et al., 2001; Coffey et al., 2004; Friggens et al., 2004b; Pryce and Harris, 2006; Roche et al., 2006a, 2007a; Sumner and McNamara, 2007) before replenishing lost tissue reserves (Coffey et al., 2004; Berry et al., 2006b; Pryce and Harris, 2006; McCarthy et al., 2007; Roche et al., 2006a, 2007a; Sumner and McNamara, 2007). However, what makes dairy cows unique among all other mammalian species has been the intense transgenerational genetic selection for early lactation and total milk production during the last 50 yr (Dillon, 2006). Such selection pressures have resulted in many physiological changes that facilitate greater mobilization of energetically important tissues in dairy cows than other mammals (McNamara and Hillers, 1986b; Smith and McNamara, 1990; Chagas et al., 2009; 
Lucy et al., 2009), and this effect of genetic selection for milk production has been demonstrated in genetic strain comparison studies under different management strategies (McNamara and Hillers, 1986a,b; McNamara, 1989; Smith and McNamara, 1990; McNamara, 1991; Kolver et al., 2002; Roche et al., 2006a; McCarthy et al., 2007; Macdonald et al., 2008; Kay et al., 2009; Lucy et al., 2009).

In addition to the effects of genetic selection on BCS (Berry et al., 2003a; Coffey et al., 2004; Roche et al., 2006a), several other cow-level factors have been reported to affect cow BCS, including parity (Pryce et al., 2001; Coffey et al., 2004; Berry et al., 2006b; Roche et al., 2007a), age within parity (Koenen et al., 2001; Berry et al., 2006b; Pryce and Harris, 2006), and season of calving (Pryce et al., 2001). Management (herd-level) factors such as stocking rate (McCarthy et al., 2007; Roche et al., 2007a; Macdonald et al., 2008), level of feeding (McNamara and Hillers, 1986a,b; McNamara, 1989; Smith and McNamara, 1990; McNamara, 1991; Roche et al., 2006a; Roche, 2007), and diet type (Coffey et al., 2004; Berry et al., 2006b; McCarthy et al., 2007; Roche et al., 2006a; 2007a) have also been reported to affect cow BCS.

The objective of this paper was to review the physiology underpinning BCS change and quantify the associations between BCS (change) and production, reproduction, and cow health and welfare. A further objective was to examine the herd- and cow-level factors that influence the BCS profile, enabling animal management toward improved farm productivity and profit and animal welfare.

\section{PHYSIOLOGY OF LIPID METABOLISM}

Changes in a cow's condition, measured over several weeks, provide gross information about the cow's current nutrient intake relative to its requirements. Although protein and mineral stores are also utilized by the cow in early lactation, the most important reserve is adipose tissue. A greater understanding of factors affecting lipolysis and lipogenesis, therefore, results in a better understanding of the factors influencing BCS mobilization and replenishment.

\section{Homeostatic and Homeorhetic Mechanisms}

During periods of chronic energy deficit, key hormone expression and tissue responsiveness alter to increase lipolysis and decrease lipogenesis, optimizing NEFA mobilization to maintain physiological equilibrium (Bauman and Currie, 1980; Bell, 1995; Bauman, 2000). This is known as homeostasis, and the net result is mobilization of adipose tissue reserves in response to the energy deficit.
Homeostatic control implies that if the nutritional environment is adequate the lactating dairy cow can meet its energy demands from DMI and tissue mobilization will be minimized. Thus, if homeostatic control were the only regulator of lipid metabolism during early lactation, increased energy intake should, in theory, abolish body lipid mobilization. However, attempts to reduce body lipid mobilization in early lactation (wk 1 to 4 postpartum) by feeding energy-rich diets have generally not been successful (Gagliostro and Chilliard, 1991; Grummer et al., 1995; Anderson et al., 2003; Ruppert et al., 2003; Roche et al., 2006a; Pedernera et al., 2008; Delaby et al., 2009), and severe feed restrictions during the same period have not always increased BCS mobilization (Roche, 2007); these data imply that another mechanism is involved in BCS mobilization during this early lactation period. This is consistent with reported effects of genetic merit for milk production and energy intake on the activity of key lipolytic and lipogenic enzymes (McNamara and Hillers, 1986a,b; Smith and McNamara, 1990). Their data led to the conclusion that early lactation lipolysis was largely genetically controlled (homeorhetic), whereas enzymes involved in lipogenesis were primarily regulated by energy intake (homeostatic). More recent studies (Roche et al., 2006a) indicate a potential genotype $\times$ diet interaction in lipogenesis (i.e., homeorhesis $\times$ homeostasis interaction), but concur with the lack of effect of diet on the homeorhesis-regulated lipolysis initiated around parturition.

There are characteristic changes in lipid metabolism during pregnancy and lactation in most mammals. Endocrine profiles change (Bauman, 2000) and lipolysis and lipogenesis are regulated to increase lipid reserves during pregnancy, and, subsequently, these reserves are utilized following parturition and the initiation of lactation (Pond, 1984; Smith and McNamara, 1990; Chilliard et al., 2000; Knight, 2001; Theilgaard et al., 2002; Friggens, 2003; Sumner and McNamara, 2007). These changes occur not as a function of a changing nutritional environment, but rather as a function of physiology (i.e., stage of lactation). This is homeorhetic or teleophoretic control of lipid metabolism.

The concept of homeorhesis has been around for decades (Waddington, 1957; Monod, 1970; Bauman and Currie, 1980; Chilliard, 1986), and the implication behind the concept is that the animal has a genetic drive to safeguard important biological functions such as survival of the neonate (through provision of milk) or reproduction. This drive can only be fulfilled if the necessary resources are partitioned to them by "orchestrated or coordinated changes in metabolism of body tissue, necessary to support a physiological state" (Bauman and Currie, 1980). 


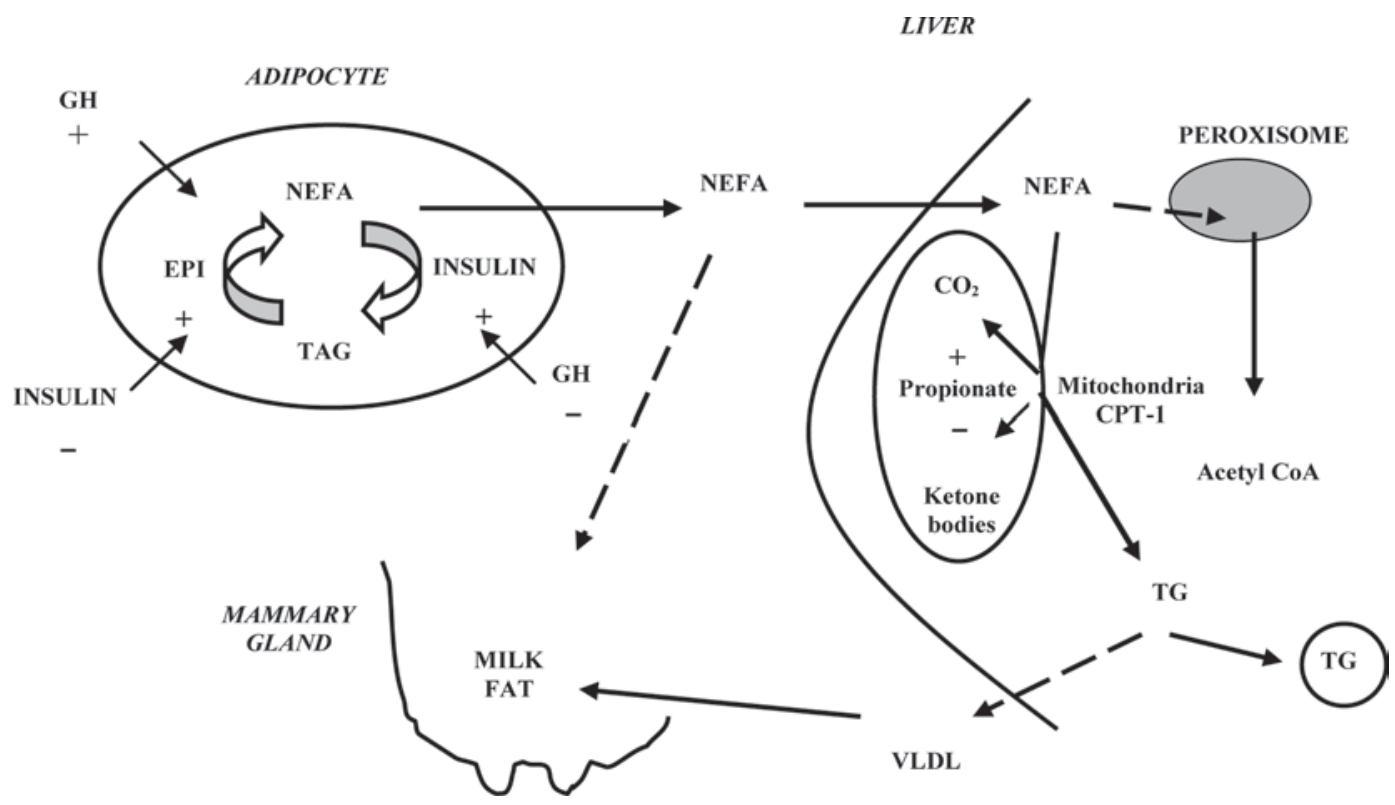

Figure 1. Schematic representation of lipid metabolism in the transition dairy cow. Positive signs $(+)$ indicate stimulation and negative signs ( - indicate inhibition. Dashed lines are processes that occur at low rates or only during certain physiological states. CPT-I $=$ carnitine palmitoyltransferase I, EPI = epinephrine, $\mathrm{GH}=$ growth hormone, $\mathrm{TG}=$ triglycerides, $\mathrm{TAG}=$ triacylglycerol, and $\mathrm{VLDL}=\mathrm{very}$ low density lipoproteins. Adapted from Drackley (1999).

Thus, regulation of lipid metabolism is regulated by both homeostatic and homeorhetic mechanisms. Homeostatic regulators of lipid metabolism are nutritionally sensitive, whereas homeorhetic regulators are largely nutritionally insensitive, instead being a function of physiological state. Regulation and coordination of energy intake and postabsorptive nutrient partitioning, in particular lipid metabolism, are key components of the periparturient homeorhetic adaptations in the dairy cow (Table 1$)$.

\section{Lipid Metabolism}

Adipose tissue represents the body's predominant energy reserve and consists of triglyceride-filled cells known as adipocytes (Bell, 1995). Within adipocytes, 2 metabolic processes, lipolysis and lipogenesis, are continuously occurring, resulting in intracellular triglycerides constantly being degraded and resynthesized (Figure 1).

Lipogenesis. Lipogenesis occurs in ruminant adipocytes via 2 pathways: de novo synthesis and the uptake of preformed fatty acids from circulation (Bauman, 1976). Compared with monogastric animals, that use glucose for lipogenesis, ruminants use acetate (derived from rumen fermentation) as the predominant carbon source for de novo fatty acid synthesis. Acetyl CoA carboxylase (ACC), the rate-limiting enzyme in de novo fatty acid synthesis (Bauman and Davis, 1974), catalyzes the formation of malonyl-CoA, the first committed step in fatty acid synthesis. Malonyl$\mathrm{CoA}$ is then condensed with acetyl-CoA by fatty acid synthetase (FAS) to produce the first 4-carbon acyl unit, butyrate. Acetate is the primary carbon source

Table 1. Metabolic adaptations associated with negative energy balance in dairy cows ${ }^{1}$

\begin{tabular}{lll}
\hline Physiological function & Metabolic changes & Tissues involved \\
\hline Milk synthesis & Increased use of nutrients (in particular glucose) & $\begin{array}{l}\text { Mammary gland } \\
\text { Adipose tissue }\end{array}$ \\
Lipid metabolism & Increased lipolysis & Decreased lipogenesis \\
Glucose metabolism & Increased gluconeogenesis & Biver \\
& Increased glycogenolysis & \\
& Decreased glucose oxidation & \\
Protein metabolism & Increased lipid $\beta$-oxidation & Muscle and other body tissue \\
\hline
\end{tabular}

${ }^{1}$ Adapted from Bauman and Currie (1980). 
for fatty acid elongation, and additional malonyl-CoAs (produced by ACC) are condensed with the growing acyl chain (via FAS) to produce longer chain fatty acids, with the primary product being palmitate (C16:0; Bauman and Davis, 1974).

In the case of fatty acid uptake from circulating lipids, lipoprotein lipase (LPL) hydrolyses plasma triacylglycerides (TAG), producing NEFA and monoacylglycerides (Fielding and Frayn, 1998). Uptake and intracellular transport of both NEFA and monoglycerides is not well understood, but is thought to be mediated by a fatty acid binding protein (Lehner and Kuksis, 1996). Adipose TAG are synthesized through either the phosphatidic pathway or the monoacylglycerol pathway, depending upon availability of glycerol-3-phosphate and monoacylglycerides (Lehner and Kuksis, 1996).

Lipolysis. During lipolysis, hormone-sensitive lipase (HSL) acts as a catalyst at the lipid droplet surface in the adipocyte to hydrolyze fatty acids at the sn- 1 and sn-3 positions. Activation of HSL by lipolytic hormones is mediated by reversible phosphorylation via cyclic AMP (cAMP)-dependent protein kinase A (PKA). Additional regulation occurs via perilipin, a hydrophobic protein associated with the lipid droplet. Perilipin phosphorylation (via cAMP-dependent PKA) is believed to be essential for HSL translocation from the cytosol to the surface of the lipid droplet, enabling fatty acid hydrolysis to occur (Yeaman, 2004). Monoacylglycerol lipase then hydrolyses the remaining fatty acid at the sn- 2 position generating 3 NEFA and a glycerol backbone (Stipanuk, 2000). Consistent with the increased lipolysis in early lactation, Sumner and McNamara (2007) reported upregulation in $\beta$-adrenergic receptors, HSL, and perilipin mRNA in adipose tissue in lactating cows relative to cows prepartum. However, these data do not reflect a downregulation of these lipolytic factors through mid-lactation, indicating their involvement in both homeorhetically and homeostatically regulated lipolysis.

Once mobilized, NEFA quickly attach to serum albumin for transport to various tissues. During high rates of lipolysis, the ratio of NEFA to albumin increases and NEFA occupy the lower affinity binding sites on the albumin molecule. This weak connection favors delivery and uptake of NEFA by energy and lipid requiring tissues (Stipanuk, 2000).

NEFA Metabolism. Circulating NEFA are metabolized via 3 pathways: they can be oxidized by the liver and skeletal muscle as an energy source; re-esterified to triglyceride in the liver; or used by the mammary gland as a source of milk fat (Figure 1; Drackley, 1999).

$\beta$-Oxidation of fatty acids in liver is localized in the mitochondrial compartment of hepatic cells and produces acetyl CoA and reduced forms of $\mathrm{NADH}$ and flavin adenine dinucleotide (FADH); these generate energy via ATP production in the citric acid cycle and electron transport chain, respectively (Stipanuk, 2000). Carnitine palmitoyltransferase-I (CPT-I) is the rate-limiting enzyme responsible for transporting cytosolic fatty acids to the mitochondria for $\beta$-oxidation (McGarry and Brown, 1997). Activity of CPT-I and subsequent fatty acid $\beta$-oxidation rates increase during negative energy balance, probably because of decreased concentrations of, and reduced sensitivity to, malonylCoA, a potent allosteric CPT-I inhibitor (Brindle et al., 1985; Jesse et al., 1986). Malonyl Co-A is a fatty acid synthesis intermediate and concentrations decrease during periods of negative energy balance, when insulin to glucagon ratios are low and lipogenesis is limited (McGarry and Brown, 1997).

When fatty acid mobilization from adipocytes is accelerated, hepatic cells convert excess acetyl CoA generated from $\beta$-oxidation into ketone bodies (acetoacetate and BHBA; Herdt, 2000). Rate of ketone body formation is directly proportional to fatty acid oxidation rates, and although acetyl-CoA conversion to ketone bodies, rather than complete $\beta$-oxidation, is less energetically efficient (Stipanuk, 2000), ketosis is an important energy-providing mechanism for dairy cows in early lactation. This is because during lactation, the majority $(>80 \%)$ of available glucose is partitioned to the mammary gland (Bell, 1995), and vital organs that cannot metabolize fatty acids as an energy source (e.g., the brain) rely on ketone oxidation for survival (Stipanuk, 2000).

An alternative pathway to hepatic NEFA oxidation is via peroxisomes, subcellular organelles present in most organs of the body (Singh, 1997). However, compared with mitochondrial $\beta$-oxidation, which generates energy in the form of reduced NADH in addition to acetyl CoA, peroxisomal $\beta$-oxidation produces hydrogen peroxide and heat; peroxisomes do not contain a respiratory chain linked to ATP formation. It is, therefore, proposed that the less energy efficient peroxisomal $\beta$-oxidation may play a role as an overflow pathway to oxidize fatty acids only during extensive NEFA mobilization (Figure 1; Drackley, 1999).

Nonesterified fatty acids that do not undergo hepatic $\beta$-oxidation are re-esterified to triglyceride and released into the circulation as very low density lipoproteins (VLDL; Figure 1). During periods of negative energy balance, hepatic capacity for fatty acid re-esterification increases. However, the VLDL export rate from the liver remains low (Bauchart, 1993), possibly because of the bovine's reduced capacity to generate apoprotein B, the key component believed to control the overall rate of VLDL synthesis and secretion (Drackley, 1999; Avramoglu and Adeli, 2004). Thus, during periods of nega- 
tive energy balance, increased hepatic NEFA uptake and re-esterification combined with inefficient VLDL release can result in hepatocyte triglyceride accumulation, a phenomenon often referred to as "fatty liver."

\section{Physiological Factors Regulating Lipid Metabolism}

Growth Hormone. Growth hormone (GH; synonymous with somatotropin) is a protein hormone released from the anterior pituitary that plays a pivotal role in the homeorhetic coordination of body fuel utilization. Concentrations increase at calving, facilitating energy release from adipose stores (Liesman et al., 1995), and the periparturient increase is exacerbated by prepartum energy restriction (Roche, 2007), implying a potential homeostasis $\times$ homeorhesis interaction.

Growth hormone is primarily regulated by 2 antagonistic hypothalamic hormones, growth hormone releasing factor (GRF) or GH-releasing hormone, a peptide synthesized in the arcuate nucleus that stimulates $\mathrm{GH}$ release, and somatostatin, produced in the paraventricular nucleus, which inhibits GH secretion (Mayo et al., 1995). In addition, ghrelin, a natural ligand of the GH secretagogue receptor and produced primarily in the oxyntic cells of the abomasum, acts synergistically with GRF to stimulate GH release (see review by Roche et al., 2008).

Growth hormone release is also under negative feedback regulation. Insulin-like growth factor-I and GH act on the anterior pituitary to inhibit GH release, on the neuropeptide $\mathrm{Y}$ neurons in the arcuate nucleus to inhibit GRF secretion, and on the somatostatin neurons in the paraventricular nucleus to stimulate somatostatin release (Chihara et al., 1981; Katakami et al., 1987; Chomczynski et al., 1988; Rogers et al., 1988; Minami et al., 1998).

Physiological actions of GH are initiated when GH binds to GH receptors (GHR) on target cells. There are 3 variants of the GHR transcript; GHR-1A, found primarily in the liver, is under developmental and nutritional regulation, whereas GHR-1B and GHR-1C are active in a wide range of tissues, including adipocytes, and do not appear to be developmentally or nutritionally regulated (Lucy et al., 2001).

In the liver, where the greatest abundance of GHR are located, binding of GH to GHR-1A initiates the synthesis and secretion of IGF-I. In addition to the negative feedback action on GH secretion, IGF-I acts to regulate the growth and function of various cells throughout the body. During the transition from gestation to lactation in the dairy cow, there is a reduced abundance of hepatic GHR-1A transcript, and, as a consequence, there is an approximately $70 \%$ decline in plasma IGF-I, despite elevated plasma GH concentrations; this phenomenon is often referred to as uncoupling of the somatotropic axis (Block et al., 2001; Lucy et al., 2001; Radcliff et al., 2003; Rhoads et al., 2004; Lucy et al., 2009). During periods of feed restriction in established lactation, GHR abundance in the liver is also reduced (Breier et al., 1988), initiating homeostasis-regulated lipolysis.

Growth hormone has a myriad of effects on adipose tissue metabolism. It enhances the lipolytic response to $\beta$-adrenergic-signals (Etherton and Bauman, 1998). Liesman et al. (1995) reported positive effects of both GRF and GH on HSL activity per gram of adipose tissue in dairy cows, and negative effects of both on adipose tissue fatty acid re-esterification. Furthermore, GH modulates insulin action through regulation of the expression of the p85a subunit of PI 3-kinase in adipose tissue (del Rincon et al., 2007). The PI 3-kinase pathway is essential in insulin-induced glucose uptake and lipid metabolism, and the insulin-mediated increase in adiponectin secretion (Okada et al., 1994; Kamon et al., 2004). Therefore, GH directly regulates ruminant adipose stores by enhancing the response to lipolytic stimuli, attenuating the lipogenic response to insulin, and inhibiting the insulin-mediated uptake of glucose by adipocytes. The net effect is the partitioning of nutrients away from adipocytes.

Insulin. Insulin is a potent regulator of lipogenesis (Vernon, 1992) as well as an antagonist to the lipolytic actions of GH through its positive effect on hepatic and adipocyte GHR abundance (Rhoads et al., 2004). Hypo-insulinemia and decreased insulin responsiveness (increased insulin resistance) of skeletal muscle and adipose tissue occur simultaneously in early lactation (Bell and Bauman, 1997; Vernon and Pond, 1997), resulting in increased glucose availability for insulin-independent uptake by the mammary gland and greater mobilization of tissue reserves. Dairy cows selected for increased milk yield have greater insulin resistance (Chagas et al., 2009), which is associated with greater body lipid mobilization and a lower BCS nadir (Smith and McNamara, 1990; Roche et al., 2006a; Kay et al., 2009).

Leptin. Leptin, a protein hormone secreted almost exclusively by adipocytes (Zhang et al., 1994) is representative of overall adiposity (total white adipose tissue mass and adipocyte hypertrophy) and serves as an intake satiety signal by acting predominantly on regions of the brain involved in regulation of energy metabolism (see review by Roche et al., 2008). The homeorhetically regulated decline in leptin immediately postpartum in the lactating dairy cow, as a consequence of energy deficit and reduced leptin gene expression (Leury et al., 2003), matches almost exactly the plasma insulin profile at that time (Bell, 1995; Block et al., 2001). Insulin upregulates leptin expression in rodents, humans (Ahima and Flier, 2000; Considine, 2001), and cows 
(Houseknecht et al., 2000; Leury et al., 2003). However, the plasma leptin response to insulin is 6 times greater during late pregnancy than during lactation (Leury et al., 2003), consistent with reduced adipose tissue glucose uptake in early lactation. The exact mode of action of insulin on leptin synthesis in the ruminant remains to be determined.

Growth hormone does not independently affect leptin synthesis but is thought to act indirectly by inhibiting the insulin-mediated glucose uptake by adipocytes (Houseknecht et al., 2000; Leury et al., 2003). The involvement of IGF-I in the GH-mediated effects on leptin expression is not clear.

Catecholamines. Catecholamines, such as epinephrine and norepinephrine, secreted by sympathetic nerve endings in adipocytes and the adrenal medulla, respectively, act as potent lipolytic stimulators (Bauman and Currie, 1980). These catecholamines act via G-proteins to increase adenyl cyclase production, which stimulates intracellular cAMP formation; cAMP then activates PKA, which phosphorylates and activates the regulatory subunits of both HSL and perilipin proteins, thereby increasing lipolysis (Stipanuk, 2000). McNamara (1988) reported an increased responsiveness of bovine adipose tissue to catecholamines in early lactation, consistent with periparturient homeorhetic changes to facilitate lipolysis.

\section{ASSESSING COW CONDITION}

Although it was probably evident for centuries that cows lost and gained condition during the lactation cycle, there was no simple measure of a cow's stored energy reserves until the 1970s (Stockdale, 2001; Garnsworthy, 2006). Body weight alone is not a good indicator of body reserves, as the relationship is affected by factors such as parity, stage of lactation, frame size, gestation, and breed (Grainger and McGowan, 1982; Enevoldsen and Kristensen, 1997; Stockdale, 2001; Berry et al., 2006a). In addition, because tissue mobilization in early lactation occurs as feed intake is increasing (Ingvartsen and Andersen, 2000; Berry et al., 2006b; Roche et al., 2006a; 2007a), actual decreases in body tissue weight can be masked by enhanced gastrointestinal fill, such that BW changes do not reflect changes in adipose and lean tissue weight (NRC, 2001). Andrew et al. (1994) and Gibb et al. (1992) reported that energy stores varied by as much as $40 \%$ in cows of similar BW. An independent system of assessing cow condition was, therefore, required.

Body condition was defined by Murray (1919) as the ratio of body fat to nonfat components in the body of a live animal. However, large-scale direct measurements of body adiposity were (and remain) difficult and ex-
Table 2. Relationship ${ }^{1}$ between the 10-point BCS scale used in New Zealand (NZ), the 5-point BCS scale used in Ireland (IRE), and the United States (USA), and the 8-point BCS scale used in Australia $(\mathrm{AUS})^{2}$

\begin{tabular}{llll}
\hline NZ & USA & IRE & AUS \\
\hline 1.0 & 1.82 & 1.21 & 2.74 \\
1.5 & 1.98 & 1.41 & 3.01 \\
2.0 & 2.14 & 1.61 & 3.28 \\
2.5 & 2.30 & 1.81 & 3.55 \\
3.0 & 2.46 & 2.01 & 3.82 \\
3.5 & 2.62 & 2.21 & 4.09 \\
4.0 & 2.78 & 2.41 & 4.36 \\
4.5 & 2.94 & 2.61 & 4.63 \\
5.0 & 3.10 & 2.81 & 4.90 \\
5.5 & 3.26 & 3.01 & 5.17 \\
6.0 & 3.42 & 3.21 & 5.44 \\
6.5 & 3.58 & 3.41 & 5.71 \\
7.0 & 3.74 & 3.61 & 5.98 \\
7.5 & 3.90 & 3.81 & 6.25 \\
8.0 & 4.06 & 4.01 & 6.52 \\
8.5 & 4.22 & 4.21 & 6.79 \\
9.0 & 4.38 & 4.41 & 7.06 \\
9.5 & 4.54 & 4.61 & 7.33 \\
10.0 & 4.70 & 4.81 & 7.60
\end{tabular}

${ }^{1}$ Figures outside the range measured are extrapolated from the regression equations: USA $=1.5+0.32 \mathrm{NZ}$; IRE $=0.81+0.4 \mathrm{NZ}$; and AUS $=2.2+0.54 \mathrm{NZ}$.

${ }^{2}$ Source: Roche et al. (2004).

pensive. As a result, multiple systems to subjectively appraise the stored energy reserves of dairy cattle were introduced in the 1970s and 1980s, and scores were assigned to reflect the degree of apparent adiposity of the cow; these scores were termed body condition scores. Lowman et al. (1973) were the first to introduce a BCS scale (4-point) for dairy cows, adapting a scoring system used to rank beef cattle. Further BCS systems evolved independently across the world, with a 6-point scale proposed in the UK (0 to 5; Mulvaney, 1977), an 8-point scale developed in Australia (1 to 8; Earle, 1976), a 5-point system established in the United States (1 to 5; Wildman et al., 1982; Edmonson et al., 1989), and a 10-point scale introduced in New Zealand (1 to 10; Macdonald and Roche, 2004; Roche et al., 2004). A comparison of BCS using 4 of the different systems is presented in Table 2 (Roche et al., 2004).

As the importance of cow condition to production, reproduction, and cow health became better defined, the BCS scales have become more definitive (i.e., greater precision) and the assessment method has expanded to encompass more body regions. For example, the anatomy considered in the original scale proposed by Lowman et al. (1973) included only the lumbar vertebrae and the tail-head; most systems now include the thoracic and vertebral region of the spinal column (chine, loin, and rump), the ribs, the spinous processes (loin), the tuber sacrale (hip or hook bones), the tuber ischii (pin bones), the anterior coccygeal vertebrae (tail 
head), and the thigh region (Roche et al., 2004), retaining those important points identified by Lowman et al. (1973), but expanding the assessment to provide a more complete picture of the energy reserve status of the cow.

Irrespective of the scale used, low values reflect emaciation and high values equate to obesity. The effectiveness of BCS in estimating available energy reserves was outlined by Wright and Russel (1984), who reported a strong positive relationship $(\mathrm{r}=0.93)$ between BCS and the proportion of physically dissected fat in Friesian cows. Otto et al. (1991) also reported relatively strong correlations $(\mathrm{r}=0.75)$ between BCS and the amount of dissected body fat. Waltner et al. (1994) evaluated several methods of estimating "body adiposity" against observed body fat and reported a strong correlation between BCS and observed body fat $(\mathrm{r}=0.83)$, with only the diameter of the fat cells in the abdominal depot (r $=0.88$ ) superseding BCS as a method of estimating body fat.

\section{Accuracy of BCS Assessment}

Although modern BCS systems are more definitive than the early versions proposed, limitations of these scoring systems must still be recognized. Body condition score assesses the level of subcutaneous fat a cow possesses with reasonable accuracy $\left(\mathrm{r}^{2}=0.89\right.$ for Friesian cows; Wright and Russel, 1984), but poorly predicts inter- and intramuscular fat $\left(\mathrm{r}^{2}=0.43\right.$; Wright and Russel, 1984). The latter stores are major depot regions containing 35 to $45 \%$ of body fat. These data, therefore, imply that BCS may be less accurate in thin cows with little subcutaneous fat. This conclusion is consistent with that of Ferguson et al. (1994). They confirmed that BCS can be assessed to 0.25-point accuracy between BCS 2.5 and 4.0 (5-point scale). Above or below these values, however, BCS could only be differentiated on 0.5-point differences, highlighting the lack of association among subjective BCS assessment and total fat stores in thin cows and, probably, the inability to accurately assess subcutaneous reserves in very fat cows. Using the conversion equations presented by Roche et al. (2004), these data imply that BCS can be differentiated to 0.5-point differences between BCS 3.0 and 7.5 and BCS 3.5 and 6.0 in the 10-point and 8-point scoring systems, respectively, but to no less than 1.0 BCS-unit differences outside this range.

A further factor influencing the accuracy of BCS assessment, which can be inferred from Roche et al. (2004), is whether the score given was based on tactile or visual appraisal of the cow. Data indicate greater variation among assessors when cows were appraised visually.
To aid consistent BCS assessment, several teams have independently produced BCS education material (Edmonson et al., 1989; DEFRA, 2001; DNRE, 2002; Macdonald and Roche, 2004). All materials tend to be a mix of pictures and text, which detail changes in the conformation of anatomical locations regarded as important with BCS change (Ferguson et al., 1994; Roche et al., 2004). Edmonson et al. (1989) evaluated one such tool and reported consistent BCS predictions with little inter-assessor variability, no significant cowassessor interaction, and no significant effect of assessor experience. In comparison, however, Kristensen et al. (2006) reported improved BCS assessment and reduced inter-assessor variability when veterinarians were first trained by expert assessors.

\section{Consistency of BCS Assessment}

Considering the subjective nature of the scoring process, determining both the inter-assessor reliability and intra-assessor consistency of BCS evaluation is important to have confidence that the process can be used across personnel, farming systems, and countries. Ferguson et al. (1994) evaluated the variation among 3 experienced and 1 less experienced assessor using the 5 -point scale, and reported that they either agreed or deviated by no more than 0.25 BCS points in over $90 \%$ of assessments. Similarly, Kristensen et al. (2006) noted $83 \%$ agreement between highly trained assessors, with repeatability of 72 to $95 \%$. However, they noted poor agreement between these assessors and 51 practicing veterinarians. Nevertheless, following training, they reported good agreement between the veterinarians and assessors, and an improved repeatability across veterinarians.

\section{Interconversion Among BCS Scales}

The commonality of the body parts assessed and the direction of BCS with increasing adiposity allows for mathematical interconversion between many of these scales. Garnsworthy (2006) presented conversion equations between the 5-point scale and the 4-point, 6-point, 8-point, 9-point, and 10-point scales:

$$
\begin{aligned}
& 1-4 \text { scale: } 4 / 3 \times \mathrm{BCS}-1 / 3 \\
& 0-5 \text { scale: } 4 / 5 \times \mathrm{BCS}+1 \\
& 1-8 \text { scale: } 4 / 7 \times \mathrm{BCS}+3 / 7 \\
& 1-9 \text { scale: } 1 / 2 \times \mathrm{BCS}+1 / 2 \\
& 1-10 \text { scale: } 4 / 9 \times \mathrm{BCS}+5 / 9
\end{aligned}
$$


These equations assume that the linear relationships between the different BCS systems reflect an equal emphasis on thin and fat cows across scales. Although this assumption may appear valid, Roche et al. (2004) reported convergence at the lower end of the BCS scales in the 4 scoring systems they evaluated:

$$
\begin{aligned}
& \mathrm{USA}=1.5+0.32 \mathrm{NZ} \\
& \mathrm{IRE}=0.81+0.4 \mathrm{NZ} \\
& \mathrm{AUS}=2.2+0.54 \mathrm{NZ}
\end{aligned}
$$

where USA and IRE refer to the 5-point scoring systems in the United States (Wildman et al., 1982) and Ireland (Mulvaney, 1977), respectively, and AUS and NZ refer to the 8-point (Earle, 1976) and 10-point (Roche et al., 2004) scoring systems in Australia and New Zealand, respectively. Unless otherwise stated, the scale used throughout this review is the 5-point scale (i.e., 1 to 5; Wildman et al., 1982), and scale interconversions are completed using the equations reported by Roche et al. (2004; Table 2).

\section{INTERCALVING BCS PROFILE}

The intercalving BCS profile is similar to an inverted milk lactation curve, declining to a nadir at 40 to $100 \mathrm{~d}$ after calving (Friggens et al., 2004b; Pryce and Harris, 2006; Roche et al., 2006a, 2007a; Sumner and McNamara, 2007) as milk production peaks, before replenishing lost body reserves (Coffey et al., 2004; Berry et al., 2006b; Roche et al., 2006a, 2007a; McCarthy et al., 2007) as the milk lactation profile declines. Consistent with this mirror image analogy, cows with superior genetics for milk production and, as a result, an elevated lactation profile have a depressed BCS profile (Roche et al., 2006a; McCarthy et al., 2007).

Although in cows fed TMR the trajectory of postnadir BCS increase is generally positive until lactation ceases, data from pasture-fed cows indicate that the shape of this profile can be influenced by nutrition. For example, New Zealand cows grazing fresh pasture exhibit a peculiar W-shaped BCS profile (Roche et al., 2007a), declining for a second time in mid-lactation, when pasture quality declines, before increasing again through late lactation. Although the effect was not as pronounced in grazing Holstein-Friesian cows in Ireland, the rate of increase in BCS post-nadir did slow down during mid-lactation in older animals (Berry et al., 2006b). Furthermore, although the duration of the data collection (up to 200 DIM) included in the analysis of national BCS data from New Zealand by Pryce and Harris (2006) was not sufficient to fully visualize the shaped lactation profile, it was evident that cows, on average, lost BCS in mid-lactation. Further support for this BCS profile in grazing dairy cows was presented in a BW profile of cows grazing pasture in Florida (Fontaneli et al., 2005), where cows underwent a period of BW loss between wk 20 and 33 postpartum. Although this W-shaped profile in grazing dairy cows may appear peculiar, it was consistent with the M-shaped milk lactation profile presented by Roche et al. (2009b), and coincides with poor pasture quality during that period of the year (as evidenced by lower pasture ME content; Roche et al., 2009a).

\section{Models to Predict and Profile Interlactation BCS Change}

Given the obvious importance of BCS and BCS change that will become evident later in this review, being able to accurately model BCS and BCS change is of great value. Such models may be used to predict the BCS of a cow at critical periods during its lactation cycle and may, therefore, be incorporated into decision support tools to guide the herd owner in remedial action. Three approaches to modeling BCS change have previously been used:

1. one that relates the observed phenomenon to an underlying biological rationale (biological or mechanistic models),

2. one that focuses more on quantifying the mean lactation profile of a sample population and the individual animal variation around that mean using statistical models, without biologically interpretable regression coefficients (regression models), or

3. one that is somewhere in between both approaches and may be loosely referred to as a parametric regression model, in which (some of) the regression coefficients have biological meaning.

Biological Models. Several nutritional models calculate changes in BCS on the basis that body lipid is solely an energy buffer (e.g., Molly; McNamara and Baldwin, 2000; CPM model; Tedeschi et al., 2008). However, because in these models body lipid is simply a reservoir for excess energy intake, they are vulnerable to seemingly insignificant systematic biases in the model parameters that can rapidly accumulate across model time-steps into sizeable errors (Ellis et al., 2006) resulting in the model animal becoming excessively and unrealistically fat or thin (McNamara, 2004; Tedeschi et al., 2006). This can be corrected by adjusting for observed changes in BCS (Tedeschi et al., 2006) but 
then the model no longer predicts BCS change. These models do not include an innate (genetic) driving force for body reserve change. In contrast, there are models of BCS change that are based on the premise that the accretion of body reserves in pregnancy and their mobilization in early lactation are evolutionary adaptations that confer an advantage to the cow in terms of safeguarding her reproductive investment (Knight, 2001; Friggens, 2003). Two key points arise from this:

1. There are genetically driven changes in body reserves (homeorhesis) that can be considered as distinct from environmentally (homeostatic) driven changes in body reserves, although they may interact (Roche, 2007).

2. It is perfectly natural for cows to lose BCS in early lactation (homeorhesis), and this loss cannot be eliminated by improved feeding (McNamara and Hillers, 1986a,b; Smith and McNamara, 1990; Roche et al., 2006a; Roche, 2007; Friggens et al., 2007).

This is conceptually different from the traditional view that an energy balance of zero (or even positive energy balance) is the desired state in early lactation. Accepting the notion of an evolutionary derived, genetically regulated process, body reserve change has been reported to improve nutritional management in practice. Including a compulsory mobilization of energy in early lactation improves prediction of feed intake during this period (Petruzzi et al., 2004; Tedeschi et al., 2006). This has also been used to predict delays in return to estrus cycling (Friggens and Chagunda, 2005; Blanc and Agabriel, 2008) and to identify viable dry cow feeding strategies (Friggens et al., 2004a; Drackley, 2009). Recently, evidence of genetically regulated tissue mobilization and accretion in dairy cows has been published (Roche et al., 2006a; Friggens et al., 2007; McCarthy et al., 2007). In these studies, environmental factors, including feeding, were kept constant and energy mobilization in early lactation was not related to the BW of cows as would be expected if mobilization were a consequence of inadequate feeding. Thus, the observed mobilization must have been animal-related (i.e., under genetic control). Quantitative genetic studies have supported this by reporting significant genetic variation in BCS change in early lactation (Pryce et al., 2001; Berry et al., 2002; Dechow et al., 2002).

Pioneering work by Garnsworthy and Topps (1982), and subsequently confirmed by other studies (see review by Broster and Broster, 1998), reported that there is a target level of BCS that the cow seeks to achieve at a certain time point in lactation. This is consistent with the lipostatic theory proposed by Kennedy (1953).
Friggens et al. (2004b) combined this information with the concepts of genetically driven mobilization in a simple model to predict changes in body lipid (and thus BCS) throughout lactation. As can be seen in Figure 2, the model assumes a target level of body lipid (CS' and $\mathrm{CS}_{\text {next }}$ in Figure 2) the cow is driven to achieve at times $\mathrm{T}^{\prime}$ and the subsequent calving. Two inputs are required: body lipid at the current calving and date of conception. Given this, the model predicts realistic profiles of body lipid throughout lactation based on the simplistic assumption that rates of body lipid change occur in a linear manner. That this assumption is reasonable in cows fed TMR was demonstrated by Friggens et al. (2007), who reported that body energy change could be adequately modeled by linear splines with turning points (knots) at d 7, 29, and 115 after calving; the knot at $\mathrm{d} 7$ corresponds well with the greatest period of negative energy balance (Roche et al., 2007a), that at $\mathrm{d} 29$ with a recoupling of the somatotropic axis, a further slowing of lipolysis, and an increase in lipogenesis (Smith and McNamara, 1990; Roche et al., 2006a; Lucy et al., 2009), and that at d 115 with the average time of conception (Friggens et al., 2007). This model cannot, however, account for a change in nutrition in mid-lactation that might alter the trajectory of BCS, as occurs in pasture-fed cows (Roche et al., 2007a). There was no evidence to suggest that different breeds or parities required different knots.

The assumptions in the model of Friggens et al. (2004b) mean that body lipid (and thus BCS) curves are composed of 2 quadratic functions of time that meet at conception; the model requires supplementary rules for the case where conception occurs before $\mathrm{T}^{\prime}$ (for details see Friggens et al., 2004b). The reason for including conception in the model is that it is assumed that the cow responds differently in 2 different time scales: days from calving for body lipid mobilization, and days from conception for body lipid accretion. This is consistent with the dual processes of homeorhesis and homeostasis occurring in different timeframes (McNamara and Hillers, 1986a,b; Smith and McNamara, 1990). Friggens and Badsberg (2007) modeled BCS curves according to these 2 time scales using exponential functions in a nonlinear mixed model. They reported significant differences between breeds and parities in BCS at the nadir of the curve, with Danish Holsteins and Jerseys having lost more BCS from calving to nadir than Danish Reds, although there was no significant difference in the rate of BCS loss. These model outputs are similar to the reported genetic effects of Roche et al. (2006a) when they compared North American and New Zealand Holstein-Friesian strains. In agreement with the findings of Gallo et al. (1996), Dechow et al. (2002), and Roche et al. (2007a), first-lactation animals in all 
3 breeds modeled had the shallowest BCS curves, with significantly different minima from second-lactation cows and a nadir that was $10 \mathrm{~d}$ later. These data indicate that the key biological constants of this model are dependent on genetic strain and parity.

It is important, however, to realize that this model (Friggens et al., 2004b) only predicts genetically driven mobilization (i.e., BCS change when nutritional conditions are not limiting). It is clear that cows respond to inadequate nutrition by greater BCS mobilization (Friggens et al., 1998; Chilliard et al., 2000). However, to date no well-defined rules exist that allow prediction of the effects of underfeeding on changes in body reserves, although some general patterns can be identified (e.g., average responses to glucogenic or lipogenic feeding; van Knegsel et al., 2005). In particular, the effects of stage of lactation and milk production level on BCS response and how they interact with parity and genetic strain remain to be quantified. Current understanding of nutrient partitioning is insufficient to allow prediction of BCS profiles in response to different nutritionally limiting conditions. This is the major limitation of the current biological models and should be a focus of future research.

Regression Models. The second category of models to describe changes in BCS between consecutive calving events may be loosely referred to as regression models. The models are not always based on a prior knowledge of BCS profiles, although some knowledge is important to justify the number of parameters in the model. One of the most commonly used statistical approaches to modeling BCS profiles is random regression modeling (Coffey et al., 2002; Berry et al., 2006b). Using this approach, the mean BCS lactation profile of the sample population is modeled using highorder orthogonal polynomials, whereas individual cow deviations from the mean lactation profile are modeled using random regressions based on quadratic or cubic orthogonal polynomials. Legendre polynomials are generally the orthogonal polynomials of choice (Coffey et al., 2002; Berry et al., 2006b). However, because of the mathematical properties of a polynomial, which places relatively more weight on observations at each extremity, random splines may also be used to help reduce any erratic profiles where data are limited (Misztal, 2006). Random regression models are commonly used in quantitative genetic studies, where the desired objective is to estimate the genetic merit of an animal for the trait under investigation (e.g., BCS) at each point along the trajectory (e.g., days postcalving). This can be used to identify germplasm associated with contrasting lactation profiles for BCS. However, in nongenetic studies, individual animal solutions from the mixedmodel equations (without the inclusion of the numera-
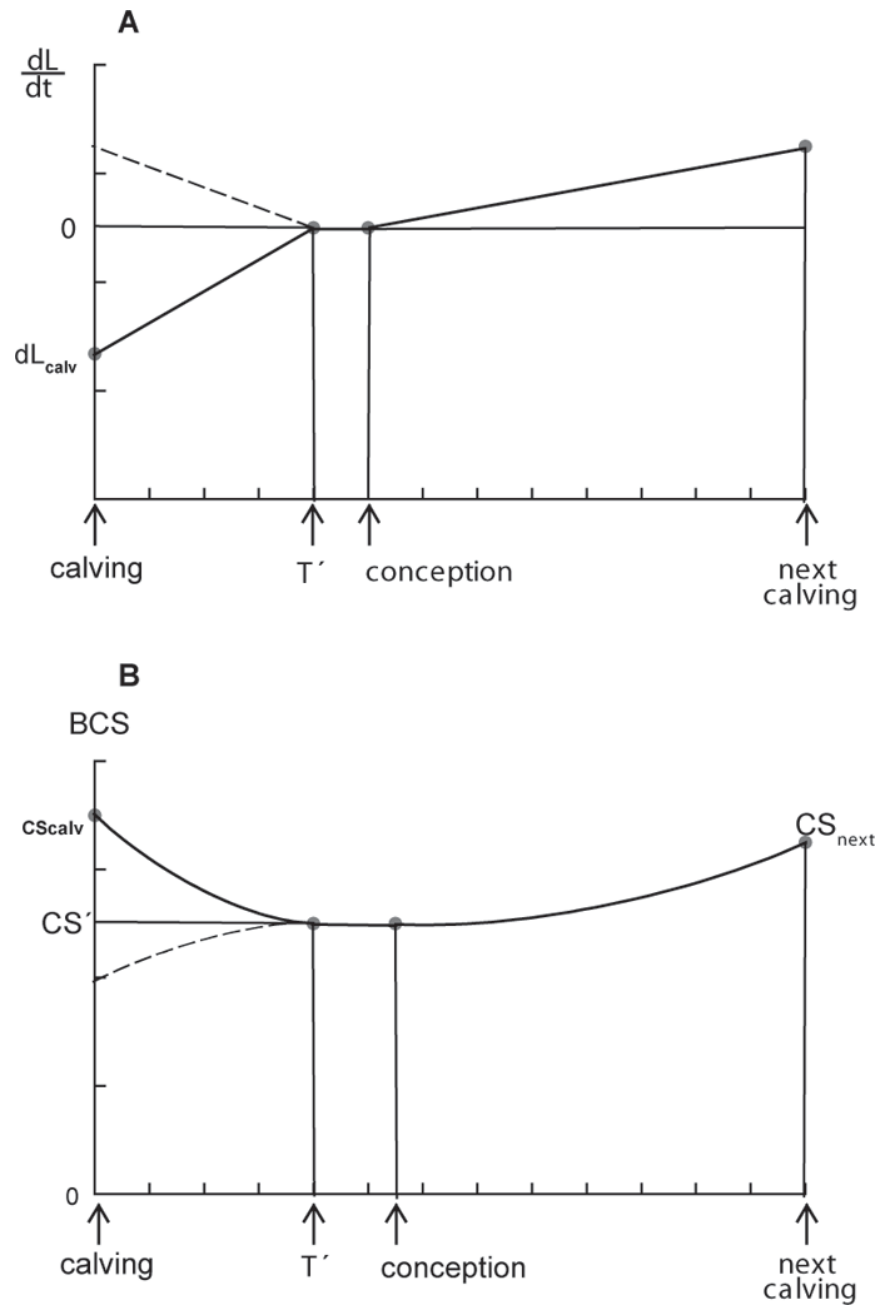

Figure 2. Graphical representation of a simple model to predict BCS patterns (Friggens et al., 2004b) based on the assumption of linear changes in rate of change of body lipid $(\mathrm{dL} / \mathrm{dt})$ with respect to time from calving, as shown in panel A. The resulting patterns of BCS are presented in panel B for 2 possible values of BCS at calving (CScalv). CScalv and the time of conception are model inputs; the rate of change of body lipid at calving (dLcalv) and the time point at which 0 rate of change in body lipid $\left(\mathrm{T}^{\prime}\right)$ is attained and the BCS at this time point $\left(\mathrm{CS}^{\prime}\right)$ are constants.

tor relationship matrix) can be summed with the mean lactation profile to obtain individual lactation profiles for BCS.

Parametric Models. Lying somewhere between the previously described biological models and regression models are parametric models, in which some of the coefficients in the model have some biological meaning. Roche et al. (2006a) and McCarthy et al. (2007) used a 3-parameter exponential function (Wilmink, 1987) developed for describing daily milk yield profiles to model the BCS of different strains of Holstein-Friesian cows receiving differing diets. The parameters of the function used related to the depth of the BCS profile, the rate of decrease in BCS postcalving, and the rate of increase in 
BCS post-nadir. The median proportion of variation in BCS explained by the function was 0.70 (Roche et al., 2006a) and 0.59 (McCarthy et al., 2007).

However, because of the incremental nature (e.g., 0.25- or 0.5-unit increments) and subjectivity of body condition scoring, fitting models to individual lactations may not be optimal for comparison of groups of cows as would be the case in designed experiments or observation studies. Using data on over 3,000 lactations from Holstein-Friesian dairy cows with frequent BCS measures, Roche et al. (2007a) developed a mathematical model to describe the intercalving BCS profile, using BCS data from cohorts of animals rather than individual animals. The function with 14 parameters comprised 4 phases that included terms associated with intercepts, rates of change, approximate timing of phase transition points, and the sharpness of these transition points. For validation, they applied their model to diverse cohorts of animals and found that it was robust and applicable across contrasting scenarios explaining between 29 and $79 \%$ of the variation depending on the cohort under investigation. However, the large number of parameters in the model required the estimation of starting values using linear robust regression fitted through each of the 4 phases separately.

Methodology Comparison. Each modeling approach has strengths and weaknesses. The benefits of the regression-type models are that they are computationally easy (especially if orthogonal polynomials are fitted) and readily allow variation to be apportioned into genetic, animal, and environmental components. Coefficients in biological models and parametric functions, on the other hand, are often strongly correlated, thereby sometimes increasing the difficulty in achieving convergence (e.g., the Roche-Berry-Boston model; Roche et al., 2007a). However, the coefficients from most regression models, typically those based on polynomials, are difficult to interpret. For example, suppose a desired outcome is identification of cows with an ability to rapidly regain condition during pregnancy. It is easy to isolate the relevant parameters in the biological model (and to some extent from parametric functions), but it is not clear how to do this in the regression model.

Regression-type models, unlike some biological models, do not, in principle, require that the data being analyzed originate from specific conditions (e.g., those that can be assumed to be nonlimiting). However, regression models do not distinguish between genetically driven and environmentally driven body reserve changes. Whether this is an advantage is debatablebecause they describe varying properties of genetically and environmentally regulated body change, regression models must be viewed as local in terms of their ability to predict future BCS change.

As the ability to quantify physiological differences between animals on a large scale increases, it seems clear that there will be benefits in combining biological and biometric approaches. This has been demonstrated for growth (Doeschl-Wilson et al., 2007), and initial steps in relation to BCS change have been made (Bryant et al., 2007; Roche et al., 2007a; Martin and Sauvant, 2009). The phase transition model of Roche et al. (2007a) can be seen as incorporating both genetically driven and environmentally driven BCS change in the same parametric model, although in the case of grazing cows, the 2 occur at different stages of lactation. Bryant et al. (2007) incorporated genetic patterns of BCS change in a model that is sensitive to the nutritional environment and allows for some degree of genotype $\times$ environment interaction. Likewise, implicit recognition of genetically regulated mobilization is being incorporated into more mechanistic models of nutrient partitioning that allow the prediction of dietary requirements (Martin and Sauvant, 2009). These initial steps, if developed further, offer the possibility of creating BCS models with greater generality and flexibility to predict BCS change for different breeds and strains in a range of nutritional environments.

\section{HERD- AND COW-LEVEL FACTORS AFFECTING COW BCS}

Considerable variation exists in BCS profiles between animals. Coefficients of variation $(\mathbf{C V})$ reported, or calculated from published statistics, range from 9 to 16\% (Ruegg and Milton, 1995; Markusfeld et al., 1997; Berry et al., 2002, 2006a) and, consistent with the BCS profile being a mirror image of the milk production profile, are similar to CV estimates for milk yield (Berry et al., 2002). Many factors contribute to this variation, and these can be loosely divided into herd- (management) and animal-level factors.

\section{Herd-Level Factors}

Herd-level factors, such as stocking rate (Roche et al., 2007a; McCarthy et al., 2007; Macdonald et al., 2008), NSC content of TMR, level of concentrates fed to grazing cows (Berry et al., 2006b; Roche et al., 2006a; McCarthy et al., 2007), or whether the animals are offered grazed grass or a complete TMR (Kolver and Muller, 1998; Washburn et al., 2002; Roche et al., 2007a) have all been reported to affect cow BCS. All of these factors are associated with feeding level or diet type. Other variables, such as the person who assessed 
the animal (Veerkamp et al., 2002) and the measurement scale (Roche et al., 2004), have also been reported to be "nuisance factors," and are usually confounded with herd (year) and are, therefore, difficult to elucidate.

Several recent experiments have explored the effect of nutrition on the interlactation profile of BCS change. Roche et al. (2006a) reported that concentrate feeding in early lactation did not affect the rate of BCS loss in early lactation, but reduced the duration of BCS loss (i.e., fewer DIM to nadir BCS), thereby slightly increasing nadir BCS. Similar conclusions were reported in an independent study in Ireland (McCarthy et al., 2007). This lack of effect of nutrition on rate of BCS loss in early lactation is consistent with the subsequent findings of others (Friggens et al., 2007; Roche, 2007; Pedernera et al., 2008; Delaby et al., 2009) and are in agreement with the general conclusion of Smith and McNamara (1990), that lipolysis is primarily regulated genetically, whereas lipogenesis is environmentally controlled. The greater post-nadir BCS gain with increasing concentrate supplementation (Roche et al., 2006a; McCarthy et al., 2007) concurs with this hypothesis. Further evidence of this effect of NSC supplementation on BCS was reported by Washburn et al. (2002) and Roche et al. (2007a), who reported consistently lower BCS across the intercalving interval in cows fed grazed grass compared with a genetically similar cohort fed TMR; although this effect of diet NSC may be influenced by cow genetic merit for milk production (Roche et al., 2006a), Washburn et al. (2002) reported that the effect was independent of breed.

The reason for the inconsistent effects of diet in early or mid to late lactation is not clear. However, it is probably associated with the physiological effects of GH and insulin discussed previously (i.e., the genetically driven BCS mobilization is mediated by the homeorhetic changes in the somatotropic axis acting on the homeostatic control of body reserve mobilization). Early lactation lipolysis is facilitated by an uncoupling of the somatotropic axis (Lucy et al., 2009) and a consequential elevated secretion of GH and a state of insulin resistance (Chagas et al., 2009) combined with low circulating insulin concentrations. Lucy et al. (2009) reported a recoupling of the somatotropic axis between 28 and 56 DIM in New Zealand Holstein-Friesian cows, although they did not detect a return to the prepartum expression of hepatic GHR in North American HolsteinFriesian by 84 DIM. This is consistent with the timing of nadir BCS in these genetic strains in an independent data set (Roche et al., 2006a). Although data presented by Roche et al. (2009c) and Chagas et al. (2009) are in agreement with the genetic strain effects on these physiological factors affecting lipid metabolism, they, respectively, reported an earlier re-coupling of the somatotropic axis and a reduction in insulin resistance in grazing cows offered more than $3 \mathrm{~kg} \mathrm{DM} / \mathrm{d}$ of concentrates in early lactation. These data imply that the genetic target for nadir BCS can be modified by nutrition, consistent with the lipogenic findings of McNamara and Hillers (1986a) and Smith and McNamara (1990), but the effect on nadir BCS is not biologically large (0.04 BCS units $/ \mathrm{kg}$ of NSC equivalent per day: 5 -point scale; $\mathrm{r}^{2}=0.87$; Roche et al., 2006a) and is affected by the genetic merit of the cow (Roche et al., 2006a). The post-nadir increase in BCS in cows offered diets containing greater concentrations of NSC is likely associated with the lipogenic and antilipolytic effects of insulin (Vernon, 1992), the circulating concentration of which would be expected to be greater due to the increased ruminal production of propionate.

\section{Cow-Level Factors}

Several cow-level factors, other than stage of the intercalving interval, are reported to be associated with cow BCS; these include BCS at calving (Roche et al., 2007a), parity (Dechow et al., 2001; Pryce et al., 2001; Roche et al., 2007a), age within parity (Gallo et al., 2001; Koenen et al., 2001; Dechow et al., 2004; Berry et al., 2006b; Pryce and Harris, 2006), season of calving (Pryce et al., 2001), year of calving (Pryce et al., 2001), breed or genetic merit (McNamara and Hillers, 1986a,b; Smith and McNamara, 1990; Roche et al., 2006a; McCarthy et al., 2007; Walsh et al., 2008), and heterosis (Pryce and Harris, 2006).

Roche et al. (2007a) reported a greater BCS loss in early lactation with increasing calving BCS, and a decreasing rate of BCS gain post-nadir with increasing nadir BCS. These data point to a within-cow target BCS that animals strive to attain (Kennedy, 1953; Garnsworthy, 2006). First-parity animals, in general, are managed to calve in greater BCS than their older herd mates (Berry et al., 2006b; Roche et al., 2007a), but fail to regain BCS post-nadir as effectively as their multiparous counterparts (Berry et al., 2006b; Roche et al., 2007a). Possible reasons for this are that firstparity animals are still growing, which adds to their cumulative energy sinks; Berry et al. (2005) reported that BW at first calving across 3 different strains of Holstein-Friesian dairy cattle represented 81 to $86 \%$ of their final mature BW. Irrespective of the reason, the inability of first-parity animals to achieve rapid postnadir BCS gains, on average, highlights the necessity for preferential management of younger cows during late lactation.

Koenen et al. (2001) reported that as age at first calving increased in Dutch Holstein and Red and White 
heifers, BCS at calving increased; heifers calving at 35 mo of age were 0.6 BCS units (9-point scale) more than heifers calving at 20 mo of age. Although others have adjusted for age at calving, nested within parity, season of calving, and year of calving, few have actually reported their effects.

Genetic makeup contributes a significant proportion of the variation in BCS among animals. Heritability estimates for BCS, which describe the proportion of phenotypic variation (after adjustment for systematic environmental effects) attributable to genetic differences in the population under investigation, vary from 0.07 to 0.60 (see Berry et al., 2008b). This means that up to $60 \%$ of the variation in BCS, within a cohort of similarly managed animals, is due to differences in their genetic makeup. The differences in estimated genetic parameters may be due to characteristics specific to the sample population under investigation, such as the frequency of the alleles at the loci influencing BCS, whether they are segregating, the size of the allelic substitution effect, and the mode of gene actions, as well as the environment the sample population was exposed to (genotype by environment interactions; Berry et al., 2003c; Roche et al., 2006a). Furthermore, the reported heritability statistics are generally narrow sense heritability estimates, which is the proportion of genetic differences that are additive (i.e., passed on from generation to generation), and therefore do not include nonadditive genetic effects. Heritability estimates for BCS change tend to be lower, varying from 0.01 to 0.09 (Pryce et al., 2001; Berry et al., 2002; Dechow et al., 2002). Substantiating the significant heritability estimates for BCS and BCS change, both McCarthy et al. (2007) and Roche et al. (2006a) in independent studies in Ireland and New Zealand, respectively, documented significant differences in intercalving BCS profiles in cows of different ancestry. Given the near unity in genetic correlations between BCS measures within lactation (Berry et al., 2003b) and across lactation (Dechow et al., 2004), it is evident that BCS at different stages of the animal's life is under the influence of similar genes or genomic regions. These data are consistent with the earlier work of McNamara and Hillers (1986a,b) and Smith and McNamara (1990), who were among the first to report a genetic influence on early lactation lipolysis and an environmental influence (i.e., nutrition) on lipogenesis. Roche et al. (2006a), however, imply that there may be a genetics $x$ environment interaction in lipogenesis. In agreement with their hypothesis, genetic correlations between BCS in different environments are not always unity (Berry et al., 2003c), implying that the gene or genomic region that influences BCS may differ depending on the prevailing environmental conditions to which the animal is exposed.
Significant differences in BCS profiles among cows of alternative breeds have also been reported (Koenen et al., 2001; Pryce and Harris, 2006; Walsh et al., 2008). Heterosis, which is the deviation of a crossbred animal from the mean of its parents, has previously been reported to affect BCS; Pryce and Harris (2006) reported $100 \%$ heterosis estimates of between 0.06 and 0.07 greater BCS units (10-point scale), depending on the parental breeds.

\section{BCS AND PRODUCTIVITY-RELATED TRAITS}

\section{Dry Matter Intake}

For many years, the main focus in the selection of dairy cows has been on milk production traits (Miglior et al., 2005). This has led to an increase in production, which has not been followed by a corresponding increase in DMI capacity (van Arendonk et al., 1991). There is general agreement that this genetic ability to eat is influenced by calving BCS and BCS in early lactation, with the majority of studies reporting a negative association between BCS and DMI (Garnsworthy and Topps, 1982; Treacher et al., 1986; Garnsworthy and Jones, 1987).

The importance of the fat depot in the regulation of DMI was hypothesized by very early physiologists such as Darwin (1859) and Bernard (1856). One of the most important theories in this field was proposed by Kennedy (1953), that the effect of the hypothalamus in anorexigenic or orexigenic signals is primarily lipostatic or adipostatic, suggesting that genetic factors dictate an individualized level of body adiposity, which animals strive to maintain. Kennedy (1953) noted that the size of body stores remained relatively constant in adult animals allowed to eat balanced diets without interference. He deduced that animals appeared to regulate their stored reserves. Deviations from the defended level of adiposity trigger compensatory changes in hunger and satiety regulators and energy expenditure that persist until the level of body fat is restored (Cummings and Foster, 2003; Roche et al., 2008). Several studies have since confirmed the validity of this hypothesis, with animals on restricted allowances increasing their intake beyond that of control comparisons when given unrestricted access to feed, until such time as their BW returned to that of the control cohort (Bernstein et al., 1975; Mitchel and Keesey, 1977). These results point to a DMI-regulating effect of adipose tissue.

More direct evidence of this was reported by Broster and Broster (1998) and Tolkamp et al. (2006) in dairy cows and sheep, respectively; they demonstrated a negative association between body fatness and DMI. Similarly, McCann et al. (1992) and Caldeira et al. (2007) 
both reported a rapid increase in DMI in lean sheep fed ad libitum until a BCS of 3.7 to 4.0 (5-point scale) was obtained, at which point DMI declined rapidly to a constant lower level such that BW was maintained.

Over the last $15 \mathrm{yr}$, adipose tissue has become recognized as a true and complex endocrine organ. Among the large number of recognized hormones produced by the adipocytes, leptin appears to be the main regulatory signal of DMI (Zhang et al., 1994). However, it is probable that the adipose tissue might also have an integrative role in the regulation of voluntary DMI; leptin expression and secretion are regulated by external environmental factors and several other hormonal systems, themselves sensitive to metabolic status, and adrenergic inputs (Chilliard et al., 2005; Zieba et al., 2005; Blache et al., 2006). These may also be involved in DMI regulation.

Although the mechanisms are not yet well understood, it is widely accepted that cow BCS is negatively associated with DMI (Roche et al., 2008), consistent with lipostatic theory (Kennedy, 1953). Because of this, postcalving BCS loss and the size of the negative energy balance increase with increasing calving BCS (Roche et al., 2007a). Effects of BCS on DMI must be considered when determining an optimal BCS. Further research will quantify the extent of the effect of BCS on DMI, and the interaction, if any, with cow- and herd-related factors.

\section{Milk Production}

As well as providing long-chain fatty acids for milk fat production, increased lipolysis provides an energy substrate for non-mammary tissues in early lactation, thereby sparing glucose for mammary lactose synthesis and increasing milk yield (Bauman and Currie, 1980). A positive association would, therefore, be expected between calving BCS and postpartum BCS loss, and a negative association expected between nadir BCS and milk production. This relationship between BCS and milk production is consistent with fitted functions presented by Roche et al. (2006a, 2007a) and McCarthy et al. (2007), who both depicted BCS profiles as mirror images of the milk lactation profile. A significant program of research in this area from Washington State University over the last $20 \mathrm{yr}$ has implicated increased milk production with increased activity of lipolytic enzymes in adipose tissue, and more recently with greater expression of genes involved in body fat mobilization (McNamara and Hillers, 1986a b; Smith and McNamara, 1990; Sumner and McNamara, 2007). Energy stores are, therefore, a key component of milk production. There are, however, inconsistencies in the associations between BCS and BCS change and milk production, with data indicating both positive and negative relationships.

Garnsworthy and Topps (1982) evaluated the effect of reasonably disparate calving BCS $(1.7,2.7$, or 3.7 ; 4-point scale) on milk production, feed intake, and early lactation BCS change. They reported a negative effect of calving BCS on milk yield, with thinner cows producing greater milk yields than fatter cows because of a greater DMI. Subsequent research (Garnsworthy and Jones, 1987) confirmed their results. These data are also consistent with those reported by Treacher et al. (1986), who reported that moderately conditioned cows at calving produced more milk than fat cows $(2.8$ vs. 3.9 ; 5 -point scale). In most cases, however, milk fat content increased with increasing calving BCS. By comparison, in a recent review, Stockdale (2001) reported an increase in milk yield and fat content from thin to moderate BCS at calving. These seemingly contradictory results point to a possible nonlinear association between BCS and milk yield.

Although not concluded from the data, results reported in the reviews by Broster and Broster (1998) and Stockdale (2001) suggest a curvilinear association between BCS and milk production. Consistent with this, Waltner et al. (1993) presented a quadratic relationship between calving BCS and milk yield, with production during the first 90 DIM peaking at calving BCS 3.5. This has been substantiated by more recent studies (Figure 3). Roche et al. (2007b) reported an optimum calving BCS for milk production of 3.5 (6.5 on their 10-point scale), whereas Berry et al. (2007a) reported a slightly higher optimum (4.25), although cow numbers at the upper end of the BCS scale were scarce (less than $5 \%$ of calving records were $>$ BCS 4 ; Berry et al., 2007a). Irrespective of the actual optimum, the positive milk yield response to BCS declined with increasing BCS. Waltner et al. (1993) predicted that the increase in 90-d FCM yield from calving BCS 1.0 to 2.0 was $619 \mathrm{~kg}$, but the increase was reduced by $147 \mathrm{~kg}$ of FCM for every 0.5 BCS unit increase thereafter. The nonlinear relationship between calving BCS and subsequent milk production provides a plausible explanation for the inconsistent results presented in the literature. Reasons for the inconsistency include the following: 1) an insufficient number of treatments to determine an optimum (3 or fewer); 2) selection of treatments that spanned the optimum, thereby resulting in little or no detectable effect of calving BCS on milk production, or that contained too few cows to detect the small effects of BCS change in this range; and 3) selection of treatments where the average of the thin cows was, in fact, equivalent to moderate condition and, therefore, 


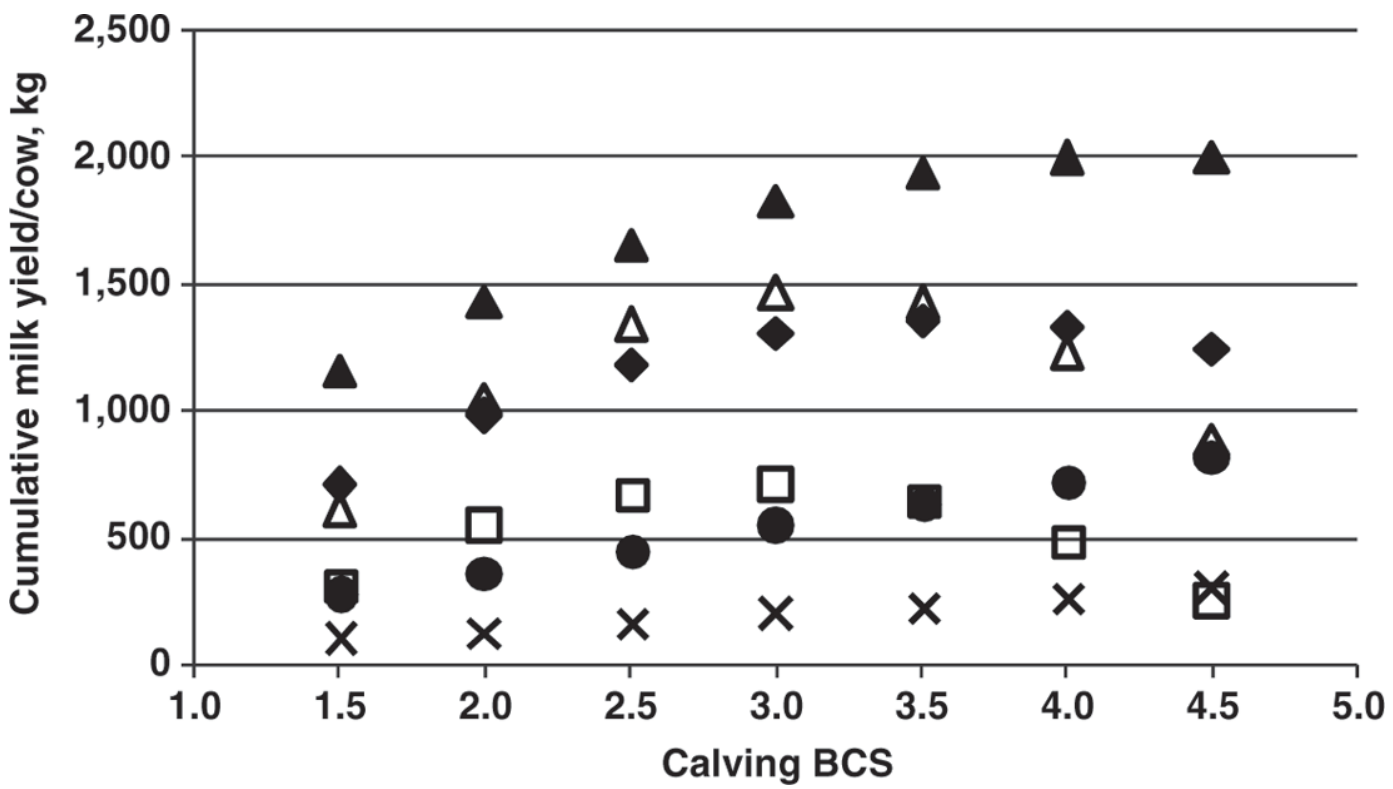

Figure 3. Association between calving BCS (5-point scale) and 60-d ( $\square$ ) and 270-d $(\Delta)$ milk yield in New Zealand (Roche et al., 2007b), 60-d $(\times)$ and 305-d $(\boldsymbol{\Lambda})$ milk yield in Ireland (Berry et al., 2007a), 90-d $(\checkmark)$ milk yield in the United States (Waltner et al., 1993), and 180-d (-) milk yield in Israel (Markusfeld et al., 1997). The 10-point scale (Roche et al., 2007b) was converted to the 5-point scale using the conversion equations of Roche et al. (2004).

close to the optimum for milk production (e.g., 1.7 on a 4-point scale; Garnsworthy and Topps, 1982, or 2.8 on a 5-point scale; Treacher et al., 1986).

Another reason for the apparent discrepancy between older studies and more recent studies may be the genetics of the animals included in the studies. Breeding programs in dairy cattle have altered the characteristics of the modern dairy cow, which may in turn affect the associations among BCS and performance indicators. Irrespective of the inconsistency in published results, the collective literature makes a compelling case for an optimum calving BCS for milk production of between 3.0 and 3.5 in Holstein-Friesian dairy cows (5-point scale; between 5.0 and 5.75 and 5.0 and 6.5 in the 8- and 10-point scales, respectively), with further increases resulting in reductions in milk yield and protein percentage, although the association with milk fat percentage is positive.

Genetic selection for increased milk production has resulted in homeorhetic changes in early lactation cows, such as lower levels of insulin and greater peripheral insulin resistance (Chagas et al., 2009). The greater milk and fat yield with increasing BCS up to 3.5 is probably a result of a greater availability of energy for the cow, thereby sparing glucose production for lactose synthesis. By comparison, the reduction in milk yield when the optimum calving BCS is surpassed is probably a result of lower DMI in overconditioned cows (Garnsworthy and Topps, 1982), with the increased tis- sue available for mobilization failing to overcome the BCS-mediated hypophagia, and possibly a subclinical malaise associated with excessive BCS mobilization (e.g., ketosis, fatty liver).

Despite the nonlinear nature of the relationships, the similarity in the association between milk yield and either calving BCS or BCS change across various studies is remarkable (Figure 3), especially considering the large differences in systems of scoring BCS, farm systems (intensive grazing vs. confinement), diets (pasture vs. TMR), and mean total milk production/cow represented (e.g., 4,141 and 9,541 kg of milk in the studies of Roche et al., 2007b and Waltner et al., 1993, respectively). For example, the milk yield response to calving BCS reported by Roche et al. (2007b) in pasture-fed cows is similar to that reported by Waltner et al. (1993) and Domecq et al. (1997a) in TMR-fed cows. Domecq et al. (1997a) reported a $545.5 \mathrm{~kg} / \mathrm{cow}$ increase in 120-d milk yield with incremental increases in BCS between dry-off and calving. In comparison, Roche et al. (2007b) reported an increased 270-d milk yield of $628 \mathrm{~kg} / \mathrm{cow}$ with a 1.0 -unit increase in calving BCS between 2.0 and 3.0, although the effect was nonlinear. Similarly, Bourchier et al. (1987) reported a $5 \mathrm{~kg} / \mathrm{cow}$ per day increase in milk yield when calving BCS increased from 1.25 to 2.25. But this response declined to only $1 \mathrm{~kg} / \mathrm{cow}$ per day for a further increase of 1.5 BCS units at calving. A similar trend in the peak milk response to calving BCS was evident in the data 
set presented by Roche et al. (2007b; 5.6 and $2.9 \mathrm{~kg} /$ cow per day, respectively). Both of these studies are also consistent with the results presented by Stockdale (2004a,b; 2005), who also reported a 1.0 to $1.1 \mathrm{~kg} / \mathrm{d}$ milk yield response per unit change in calving BCS from 4 to 6 (8-point scale). Results presented by Roche et al. (2007b) also point to a $1.0 \mathrm{~kg}$ of milk/d per BCS unit, when calving BCS increased in the bottom half of the range described by Stockdale (2004a,b, 2005). The consistency in the reported results raises 2 important points:

1. The calving BCS associated with greatest milk production is 3.5. However, there appears to be very little increase in milk production by increasing calving BCS beyond 3.0, irrespective of cow milk yield or whether cows are being fed TMR in confinement versus being intensively grazed on pasture (Waltner et al., 1993; Roche et al., 2007b).

2. Experimental studies investigating the relationship between calving BCS and an applied treatment (e.g., postcalving concentrate supplementation) need to account for the nonlinear nature of the milk yield response to calving BCS and include at least 3 , and preferably 4 , calving BCS treatments with sufficient divergence to account for the quadratic response.

Both Roche et al. (2007b) and Berry et al. (2007a) presented the associations between the general shape of the lactation profile and calving and nadir BCS, and BCS change between calving and nadir. These profiles explain, in part, the nonlinearity of the previously discussed relationship between these BCS parameters and lactation milk yield. Roche et al. (2007b) reported that calving and nadir BCS were nonlinearly associated with the height of the lactation curve and the slope of the post-peak decline (lactation persistency). In their study, the height of the lactation curve was positively associated with calving and nadir BCS up to BCS 3.5 (BCS of 6.5 in the 10-point scale) and 3.0 (BCS of 4.5 in the 10-point scale), respectively; the height of the lactation curve declined with BCS greater than these optima. In comparison, lactation persistency was negatively associated with calving and nadir BCS up to BCS 3.5 (BCS of 6.5 in the 10-point scale) and 2.75 (BCS of 4.0 in the 10-point scale), respectively, implying a reduced persistency up to those BCS and an increased persistency above them. A reduced persistency with increasing BCS is consistent with the timeline of BCS mobilization and the cessation of nutrient supply from tissue stores being directed toward milk production. It is also consistent with the results of Land and Leaver
(1981) and Treacher et al. (1986). Neither calving nor nadir BCS was associated with the rate of increase in milk production to peak (parameter $b$ ).

The change in BCS between calving and nadir was linearly associated with all 3 parameters of the lactation profile, such that greater postcalving BCS loss increased the height of the lactation profile and the rate of milk yield increase to peak, but reduced lactation persistency. Increasing one factor that contributes to total milk yield (e.g., height of the lactation curve) while decreasing another (e.g., lactation persistency) could potentially result in nonlinear associations between postcalving change in BCS and lactation milk yield. Both Roche et al. (2007b) and Berry et al. (2007a) reported such a nonlinear association, with lactation milk yield increasing with BCS loss postcalving, up to between 0.5 BCS units (Roche et al., 2007b; 1.5 BCS units in the 10-point scale) and 1.5 BCS units (Berry et al., 2007a), and decreasing with further BCS loss.

Published associations among BCS variables and milk production imply a nonlinear effect of calving and nadir BCS, and postcalving BCS change and milk yield, implying the existence of an optimum. Despite large differences in the experimental models tested, there is consistency in the BCS recommendations to maximize milk production; cows should calve at approximately BCS 3.5 (5.75 and 6.5 BCS units in the 8- and 10-point scales, respectively), although there is little milk yield difference between BCS 3.0 and 3.5. Furthermore, they should lose no more than 0.5 to 1.0 BCS units postcalving (1.0 and 1.5 BCS units in the 8- and 10-point scales, respectively). Calving and early lactation BCS are generally positively associated with milk fat and protein content.

\section{Reproduction}

Successful reproduction is dependent on several different physiological functions operating optimally. A cow must ovulate a high-quality oocyte, which must then be fertilized. The resultant embryo must produce sufficient signaling proteins to alert the dam to its presence and avoid the pregnancy-terminating increase in prostaglandins, the uterine environment must be receptive to implantation, and successful implantation must occur. All of these factors can be influenced by historical and current cow energy balance. In fact, energy balance is the most likely non-management factor to influence reproductive performance (Stockdale, 2001).

Because of the known physiological effects of energy status (BCS at a time point) and energy balance (BCS gain or loss, and rate of gain or loss) on the duration of anestrous postpartum and the likelihood of a successful pregnancy, several studies have investigated the asso- 
ciations among BCS variables and reproductive success (Table 3). Although there has been some inconsistency in these research findings, most recent studies suggest a positive association between increased BCS at calving and nadir, reduced postcalving BCS loss (i.e., less extent of negative energy balance), shorter DIM to nadir $\mathrm{BCS}$, and BW gain following the planned start of mating (PSM; Garnsworthy and Topps, 1982; Grainger et al., 1982; Butler and Smith, 1989; Beam and Butler, 1999; Buckley et al., 2003; Roche et al., 2007c) and an earlier attainment of successful pregnancy. Although there is general agreement regarding the importance of energy stores and energy balance on reproduction, there are some inconsistencies in actual relationships. Some of these inconsistencies may reflect differences in how either BCS (e.g., different scale or time point) or the reproduction variable (e.g., interval fertility trait versus pregnancy or submission trait) is defined, a nonlinear association with BCS at a particular time point on the reproduction variable of interest, which was not fully accounted for in the experimental design or the statistical model, different breeds or genetic strains within breeds, which may also influence mean performance, treatment (e.g., nutritional or hormonal) of animals in the period surrounding the BCS or fertility measures, or the inherent interaction between BCS at different time points (e.g., correlation between BCS at calving and nadir).

BCS and Postpartum Anestrus. Although a period of postpartum anestrus is normal in the dairy cow, if too long, it will extend into the breeding season, particularly of seasonally bred cows and will thereby delay the timing of pregnancy and increase the risk of reproductive failure (Chagas et al., 2007). The duration of the postpartum anestrus interval (PPAI) has been associated with BCS variables by several researchers, but the significance of the association and the BCS variables that it has been associated with are not always consistent. Roche et al. (2007c) reported a negative association between whether an animal had been detected in estrus before PSM and calving and nadir BCS, and BCS loss between calving and nadir (i.e., the greater the calving and nadir BCS, and the smaller the loss between calving and nadir, the shorter the PPAI). These results are similar to the reported findings of Grainger et al. (1982) and are consistent with the general conclusions of Bewley and Schutz (2008).

Although some researchers did not report an association between calving BCS and PPAI (Garnsworthy and Topps, 1982; Ruegg and Milton, 1995; Buckley et al., 2003), there is general agreement that BCS in early lactation is negatively associated with days to first estrus, and positively associated with the likelihood of being detected in estrus before PSM (Beam and Butler, 1999;
Buckley et al., 2003; Roche et al., 2007c). In agreement with these associations, Wathes et al. (2007) reported differences in the plasma metabolite profile of cows with delayed ovarian activity consistent with greater BCS mobilization in early lactation. However, there is evidence that this effect may be nonlinear (Garnsworthy and Topps, 1982; Roche et al., 2007c), pointing to an optimum early lactation BCS (3.0 to 3.5) for successful return to estrus (Figure 4; Roche et al., 2007c).

The negative association between calving BCS and BCS change in early lactation and days to first estrus is associated with delayed ovarian activity, infrequent luteinizing hormone pulses, poor follicular response to gonadotropins, and reduced functional competence of the follicle (Chagas et al., 2007). Diskin et al. (2003) reported that negative energy balance does not affect the follicle population or the timing of recommencement of dominant follicle growth after calving, but does affect the ovulatory fate of the first dominant follicle, a possible consequence of reduced functional competence in follicles produced during a period of negative energy balance (Britt, 1991; Beam and Butler, 1999). The reason for the negative effect of BCS $>3.0$ (5.0 in the 8- and 10-point scales; Table 2) at PSM is not known, but may be associated with negative effects of leptin, adiponectin, insulin, or any other hormone associated with fat mass on hypothalamic or ovarian function.

$B C S$ and Pregnancy. Multiple regression models are consistent in their reporting that nadir BCS and BCS change between calving and nadir are negatively associated with days to conception, pregnancy to first service, and 6- and 12-wk in-calf rates (Butler and Smith, 1989; Domecq et al., 1997b; Suriyasathaporn et al., 1998; Beam and Butler, 1999; Buckley et al., 2003; Kim and Suh, 2003; Roche et al., 2007c; Wathes et al., 2007).

Butler and Smith (1989) reported very low first-service conception rates $(17 \%)$ in cows that lost more than 1 BCS unit after calving compared with cows that lost $<0.5$ BCS units (conception rate of $65 \%$ ). Similarly, although not as severe, Domecq et al. (1997b) reported reduced odds of conception to first service with increasing BCS loss in the month postpartum; cows that lost 0.4 or 0.8 BCS units were 1.17 or 1.36 times less likely to conceive, respectively, than animals that did not lose BCS in the month after calving. Roche et al. (2007c) reported a similar odds, with cows that lost 1 BCS unit (10-point scale, equivalent of 0.3 BCS units in 5-point scale; Roche et al., 2004) being 1.17 times less likely to conceive than cows that lost no BCS after calving.

Consistent with this effect of BCS loss, Buckley et al. (2003) and Roche et al. (2007c) both reported a reduced odds of a successful 6 -wk in-calf rate with declining nadir BCS; the effect was linear, with 1.28 and 1.62 
Table 3. Summary of the published effect of BCS at calving and during lactation, and BCS change in early lactation on reproductive performance with no other BCS variable adjusted for ${ }^{1,2}$

\begin{tabular}{|c|c|c|c|c|c|c|c|}
\hline Reference & $\begin{array}{l}\text { Cows or } \\
\text { lactations, } \mathrm{n}\end{array}$ & Breed & Parity & Reproductive trait & Calving BCS & $\begin{array}{l}\text { BCS during } \\
\text { lactation }\end{array}$ & $\begin{array}{l}\text { Quantity of } \\
\text { BCS loss in } \\
\text { early lactatic }\end{array}$ \\
\hline $\begin{array}{l}\text { Garnsworthy } \\
\text { and Jones (1987) }\end{array}$ & 24 cows & British Friesian & Multiparous & $\begin{array}{l}\text { Days to first heat } \\
\text { Days open } \\
\text { Number of inseminations per conception }\end{array}$ & $\begin{array}{l}\text { NS } \\
\text { NS } \\
\text { NS }\end{array}$ & & \\
\hline Ruegg and Milton (1995) & 429 cows & Holstein & Multiparous & $\begin{array}{l}\text { Days to first heat } \\
\text { Days to first service } \\
\text { Days open }\end{array}$ & $\begin{array}{l}\text { NS } \\
\text { NS } \\
\text { NS }\end{array}$ & & $\begin{array}{l}\text { NS } \\
\text { NS } \\
\text { NS }\end{array}$ \\
\hline Waltner et al. (1993) & $\begin{array}{l}\text { Approximately } \\
350 \text { lactations }\end{array}$ & Holstein & & $\begin{array}{l}\text { Days open } \\
\text { Calving to first service } \\
\text { Number of inseminations per conception }\end{array}$ & $\begin{array}{l}\text { NS } \\
\text { NS } \\
\text { NS }\end{array}$ & $\begin{array}{l}\text { NS } \\
\text { NS } \\
\text { NS }\end{array}$ & \\
\hline Domecq et al. (1997b) & 720 cows & Holstein & Multiparous & Pregnancy/conception to first service & & & Unfavorable \\
\hline Markusfeld et al. (1997) & 1,394 & Holstein & Primiparous & $\begin{array}{l}\text { Unobserved estrus } \\
\text { Inactive ovaries } \\
\text { Pregnancy/conception to first service } \\
\text { Unobserved estrus } \\
\text { Inactive ovaries } \\
\text { Pregnancy/conception to first service }\end{array}$ & $\begin{array}{l}\text { Favorable } \\
\text { Favorable } \\
\text { NS } \\
\text { NS } \\
\text { Favorable } \\
\text { NS }\end{array}$ & & \\
\hline Gillund et al. (2001) & 732 cows & Norwegian dairy breed & Multiparous & $\begin{array}{l}\text { Pregnancy/conception to first service } \\
\text { Days open } \\
\text { Number of inseminations per conception }\end{array}$ & $\begin{array}{l}\text { NS } \\
\text { NS } \\
\text { NS }\end{array}$ & & $\begin{array}{l}\text { Unfavorable } \\
\text { Unfavorable } \\
\text { Unfavorable }\end{array}$ \\
\hline Pryce et al. (2001) & $\begin{array}{l}1,211 \text { records } \\
\text { from } 534 \text { cows }\end{array}$ & Holstein & Multiparous & $\begin{array}{l}\text { Days to first heat } \\
\text { Days to first service } \\
\text { Pregnancy/conception to first service } \\
\text { Calving interval }\end{array}$ & $\begin{array}{l}\text { Unfavorable } \\
\text { NS } \\
\text { NS } \\
\text { NS }\end{array}$ & $\begin{array}{l}\text { Favorable } \\
\text { Favorable } \\
\text { Favorable } \\
\text { Favorable }\end{array}$ & $\begin{array}{l}\text { Unfavorable } \\
\text { Unfavorable } \\
\text { NS } \\
\text { Unfavorable }\end{array}$ \\
\hline Reksen et al. (2002) & 162 lactations & Norwegian dairy breed & $\begin{array}{l}\text { First } \\
\text { Second }\end{array}$ & $\begin{array}{l}\text { Days to first luteal activity } \\
\text { Days to first luteal activity }\end{array}$ & $\begin{array}{l}\text { NS } \\
\text { NS }\end{array}$ & $\begin{array}{l}\text { Favorable } \\
\text { Favorable }\end{array}$ & \\
\hline Buckley et al. (2003) & 6,433 & Holstein-Friesian & Multiparous & $\begin{array}{l}\text { Submission rate } \\
\text { Pregnancy/conception to first service } \\
\text { Pregnant within a time period }\end{array}$ & $\begin{array}{l}\text { NS } \\
\text { NS } \\
\text { NS }\end{array}$ & $\begin{array}{l}\text { Favorable } \\
\text { Favorable } \\
\text { Favorable }\end{array}$ & $\begin{array}{l}\text { NS } \\
\text { NS } \\
\text { NS }\end{array}$ \\
\hline Roche et al. (2007c) & $\begin{array}{l}928 \text { lactations } \\
2,635 \text { lactations }\end{array}$ & $\begin{array}{l}\text { Holstein-Friesian } \\
\text { Holstein-Friesian } \\
\text { and Jersey }\end{array}$ & $\begin{array}{l}\text { Multiparous } \\
\text { Multiparous }\end{array}$ & $\begin{array}{l}\text { Cycling trait } \\
\text { Submission trait } \\
\text { Pregnancy/conception to first service } \\
\text { Pregnant within a time period }\end{array}$ & $\begin{array}{l}\text { Favorable } \\
\text { NS } \\
\text { NS } \\
\text { NS }\end{array}$ & $\begin{array}{l}\text { Favorable } \\
\text { NS } \\
\text { Favorable } \\
\text { Favorable }\end{array}$ & $\begin{array}{l}\text { Unfavorable } \\
\text { NS } \\
\text { Unfavorable } \\
\text { Unfavorable }\end{array}$ \\
\hline
\end{tabular}

${ }^{1} \mathrm{NS}=$ nonsignificant; Favorable = increased BCS or reduced BCS loss improved fertility; Unfavorable = greater BCS or greater BCS loss reduced fertility performance; empty cell $=$ association not tested.

${ }^{2}$ Source: Berry et al. (2008b). 


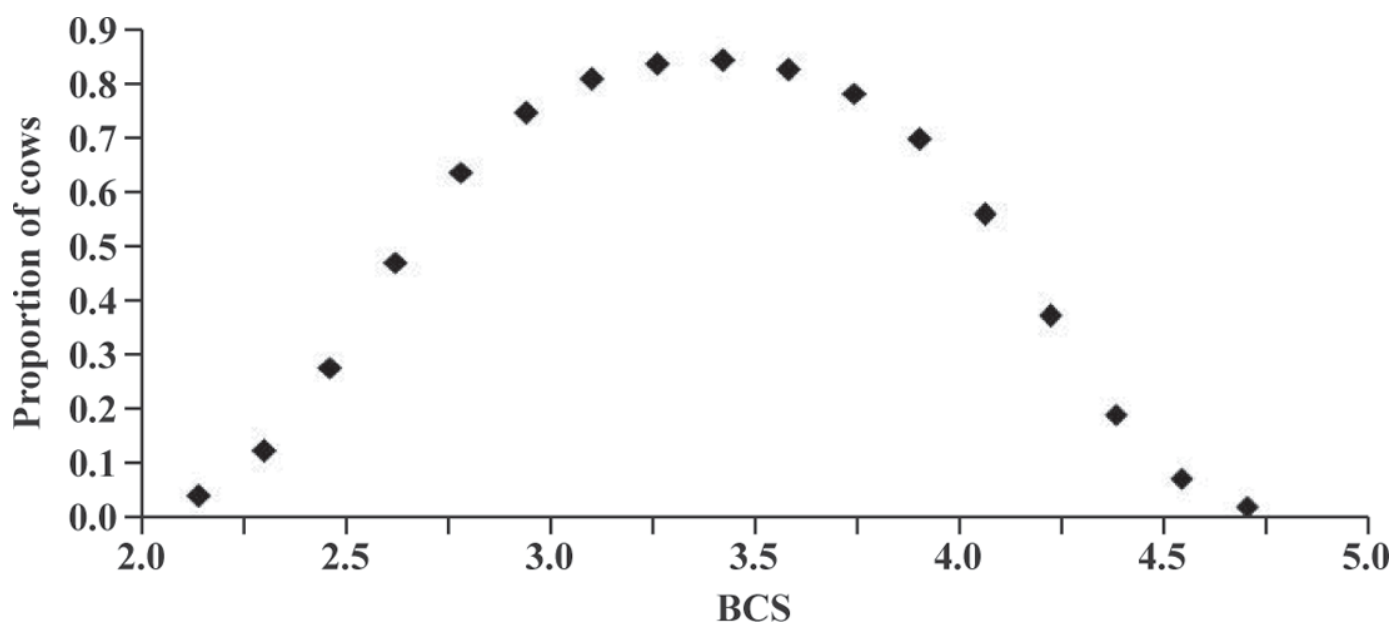

Figure 4. Association between BCS (5-point scale) at planned start of mating and the proportion of cows detected in estrus before planned start of mating. Source: Roche et al. (2007c).

increased odds of pregnancy at 6 weeks following PSM with each 0.5-unit increase in nadir BCS, respectively. Odds of a successful pregnancy at $12 \mathrm{wk}$ were 1.7 times lower in cows that were 0.5 BCS units lower at nadir (Roche et al., 2007c).

The reasons for the reduced pregnancy rate so late following PSM, when animals are apparently cycling normally, are not known. It may reflect reduced functional competence of the ovulated follicle, because of its development during negative energy balance, or it may be a result of subtle changes in steroid hormone secretions that regulate gene expression and the secretion of proteins by the endometrium, thereby affecting implantation or pregnancy recognition (Beam and Butler, 1999).

Implications. The majority of associative analyses and physiological studies agree that a decline in nadir BCS and a greater loss of BCS between calving and PSM or first AI reduce pregnancy rates in dairy cows, irrespective of feeding system. In an analysis of more than 2,500 lactations from approximately 900 cows over multiple seasons, Roche et al. (2007c) reported that a 0.5 -unit BCS difference at nadir results in a 6,8 , and $5 \%$ lower pregnancy rate to first service, at $6 \mathrm{wk}$, and at 12 wk after PSM, respectively.

Although the reported associations between calving BCS and both PPAI and successful pregnancy are not consistent across all studies, calving BCS and nadir BCS are moderately correlated with each other $(\mathrm{r}=$ 0.51; Roche et al., 2007c), with nadir BCS increasing with increasing calving BCS, albeit by a smaller amount (Roche et al., 2007a). In addition, several researchers have highlighted an inability of diet to influence the trajectory or rate of BCS loss in early lactation (Roche et al., 2006a; Roche, 2007; Friggens et al., 2007; Pedernera et al., 2008; Delaby et al., 2009). These findings indicate that the primary means for controlling nadir BCS and amount of BCS loss after calving (ignoring the genetic influence) is through managing calving BCS. Therefore, although calving BCS may not be a significant contributor to some multiple regression models relating BCS to reproduction (Buckley et al., 2003; Roche et al. 2007c), its association with nadir BCS and the physiological studies that have reported direct effects of energy reserves on the hypothalamic-reproductive axis and uterine function (Beam and Butler, 1999; Wathes et al., 2007) indicate that it is an important contributing factor to fertility outcomes.

\section{Health}

Uribe et al. (1995) and Ingvartsen et al. (2003) reported a negative genetic correlation between milk production and health in Holstein-Friesian cows, implying that selection for milk production has resulted in increased morbidity. If this is true, one would expect a negative correlation between BCS state and change in BCS and animal health (i.e., thin cows or those losing excessive amounts of BCS would be expected to be less healthy than cows with a greater BCS, losing less BCS, or those gaining BCS). The cost of impaired health status, coupled with consumer demands for animal production systems that have greater standards of animal welfare, has intensified interest in determining the association between BCS and animal health.

Although there is an increasing public perception that thin cows are welfare-compromised, there is little research to either support or refute this hypothesis. Furthermore, several previous studies have related overconditioning in dairy cattle and, as a consequence, 
greater BCS loss postcalving, or both, to impaired health (Markusfeld, 1985; Gillund et al., 2001) and altered lymphocyte (Lacetera et al., 2005) and liver function (Drackley et al., 2001). If a relationship between cow energy balance/status and health were to exist, it may manifest itself in 2 ways:

1. Thin cows or cows in severe negative energy balance may be more susceptible to infection (causal relationship; Collard et al., 2000).

2. "Unhealthy" animals may have a reduced DMI and a resultant greater BCS mobilization to satisfy the drive to milk (associative relationship; Bauman and Currie, 1980).

The relationship among BCS and cow health variables is less consistent than that among BCS and fertility (Markusfeld et al., 1997; Heuer et al., 1999; Gillund et al., 2001; Roche and Berry, 2006; Berry et al., 2007c); nonetheless, the subject is worthy of discussion in more detail.

BCS and Mastitis. There are only limited data evaluating the association between energy balance and risk of mastitis. Recently, Berry et al. (2007c) reported that the association between early lactation BCS and SCC differed by parity; first- and second-parity cows exhibited a negative relationship between early lactation BCS and SCC, whereas cows in their third lactation or greater presented with a positive relationship (i.e., SCC increased with increasing BCS postpartum). This relationship persisted for most BCS traits throughout early lactation; the interaction with parity was not evident when BCS was measured after 100 DIM, with increased BCS associated with increased SCC in all cows. Furthermore, a greater odds of clinical mastitis during lactation was associated with greater BCS (and BW) at calving, although the association with BCS was not significant and the relationship with BW was curvilinear at 305 DIM (i.e., risk of clinical mastitis increased with increasing and decreasing BW from 500 $\mathrm{kg})$. It is unclear why fatter or heavier cows in early lactation should be more prone to high SCC and clinical mastitis, but the relationship may be merely associative. However, ketosis is a disorder that occurs more frequently in overconditioned cows at calving (Duffield, 2000; Gillund et al., 2001), and it has been reported to predispose cows to clinical mastitis (Oltenacu and Ekesbo, 1994).

Ruegg and Milton (1995) and Heuer et al. (1999) did not identify a relationship between BCS and clinical mastitis, and cited a lack of overconditioned animals in their data sets as a possible reason. Similarly, only a small proportion $(5 \%)$ of the cows in the data set presented by Berry et al. (2007c) would have been regarded as overconditioned at calving (BCS >3.5).

Irrespective, the published data indicate that "thinness" of mature cows does not predispose them to a greater risk of intramammary infection, although younger cows may be more susceptible to infection when thin. In comparison, overconditioning at calving (BCS >3.5) may predispose cows to a greater risk of mastitis, through associated metabolic disorders.

BCS and Periparturient Metabolic Disorders. Calving and early lactation BCS are associated with the incidence of several metabolic disorders, most importantly ketosis (Duffield, 2000; Gillund et al., 2001) and milk fever (Roche and Berry, 2006), but also displaced abomasum (Dyk, 1995) and, probably, fatty liver (Drackley, 1999).

Roche and Berry (2006) reported a nonlinear association between BCS and the incidence of milk fever. The odds of a cow succumbing to milk fever was 13 and $30 \%$ greater at a calving $\mathrm{BCS}<2.5$ and $>3.5$, respectively, compared with a calving BCS of 3.0. They explained the relationship between fatter cows at calving and milk fever as probably the result of both attenuated postcalving DMI in cows with excessive BCS (>3.5) and an increased milk production supported by catabolism of tissue reserves (Roche et al., 2005; 2007b); the increased milk protein production would increase calcium secretion in milk (because the majority of calcium in milk is contained in the casein micelle; Davies et al., 1983). A greater calving BCS would, therefore, increase the output of calcium and potentially reduce the calcium intake immediately postpartum, predisposing such cows to milk fever. The reason for increased milk fever in very thin (BCS <2.5) cows at calving is unclear, as cows in negative energy balance precalving retain periparturient eucalcemia more effectively than well-fed cows (Roche et al., 2005; Roche, 2007), but may reflect a general malaise in emaciated cows.

Similarly, Gillund et al. (2001) reported a doubling of the risk of ketosis in dairy cows with a calving BCS of $>3.5$ compared with those with a calving BCS of 3.25. This is consistent with the comprehensive review (Ingvartsen, 2006) of periparturient morbidity and its relationship to excessive BCS mobilization. Roche et al. $(2007 \mathrm{c})$ reported moderate correlations $(\mathrm{r}=0.51)$ between calving BCS and BCS loss postcalving, implying that overconditioned cows at calving would, on average, mobilize more fat in early lactation. Combined with a reduced DMI (see earlier in this review) and an increase in lactose requirements for milk production (and therefore hepatic gluconeogenesis), hepatic oxaloacetate would likely become limiting for fatty acid oxidation, and fatty acids and ketone bodies would accumulate. 
These conclusions are consistent with the metabolic profiles presented by Roche (2007), who reported an interaction between calving BCS (precalving level of feeding) and postcalving level of feeding on circulating ketone body concentrations. Plasma concentrations of BHBA were between 50 and $100 \%$ greater in cows that calved at BCS 3.0 (BCS 5.0 in the 8- and 10-point scales) and underwent a feed restriction postpartum than in cows that calved at BCS 2.85 (4.5 and 4.25 in the 8- and 10-point scales, respectively) and underwent the same feed restriction; these data and the doubling of the odds of ketosis with only a 0.25 BCS increase in calving BCS (Gillund et al., 2001) highlight the sensitivity of periparturient dairy cows to small differences in BCS with regards ketosis.

In general, it would appear that overconditioning, not low BCS, predisposes cows to an increased risk of periparturient metabolic disorders.

BCS and Lameness. There are limited data relating calving BCS with early lactation lameness. In particular, Gearhart et al. (1990) reported a positive association between BCS and lameness; cows that were BCS $>4$ at dry off were 7 times more likely to experience foot problems in the subsequent lactation. It is unclear as to whether this effect was a result of the BCS per se, or how the animals attained that BCS (laminitis associated with excessive feeding of NSC), but there are no other reported studies that found a positive association between BCS at precalving, at calving, or in early lactation on the incidence of lameness. In direct comparison, Hoedemaker et al. (2009) recently reported a negative relationship between calving and early lactation BCS and lameness, with animals in BCS $<3.0$ at calving more likely to be lame. It is unclear from these data, however, whether it was the low BCS that caused the lameness or the lameness that caused a lower BCS through reduced DMI. Ruegg and Milton (1995) and Heuer et al. (1999) failed to identify a relationship between BCS and lameness in their analyses.

BCS and Dystocia and Stillbirths. Dystocia may be broadly defined as a parturition requiring more assistance than desirable, whereas stillbirth usually includes calf mortality shortly before, during, or shortly after parturition (Meijering, 1984). Dystocia or a stillbirth have been associated with reduced milk production and increased SCC (Berry et al., 2007b), highlighting their importance to producers. Parity of the dam, sex of the calf, whether the calf was a singleton or a twin, and a linear regression on weight of the calf are all significant risk factors affecting the incidence of dystocia (Thompson et al., 1983; Peeler et al., 1994; Chassagne et al., 1999; Meyer et al., 2001; Johanson and Berger, 2003; Steinbock et al., 2003; Ettema and Santos, 2004; Berry et al., 2007b), and indicate both genetic and nongenetic associations.

Very few studies have evaluated the relationship between BCS and dystocia or stillbirths. Waltner et al. (1993) and Berry et al. (2007b) reported no association between BCS precalving or at calving, or change in BCS in the last $10 \mathrm{wk}$ before calving on the risk of dystocia or a stillbirth event. In comparison, however, Gearhart et al. (1990) reported that cows losing BCS during the dry period were at an increased risk of dystocia.

Although periparturient BCS or BCS change was not associated with dystocia or stillbirth in the analysis of Berry et al. (2007b), Roche et al. (2006b) reported an association between periconception BCS change on subsequent calf size and sex in the same data set. As calf size and male calves are positively associated with dystocia, it is possible that BCS change early in the pregnancy is a risk factor for dystocia at the subsequent parturition; however, this was not investigated by Berry et al. (2007b). Further research is required to determine the long-term risk of BCS change around conception on subsequent dystocia and stillbirths.

Although precalving BCS or change in BCS did not alter the risk of dystocia or a stillbirth event, a cow that had a difficult calving or a stillbirth had greater BCS loss post-calving and a reduced nadir BCS (Berry et al., 2007b).

$B C S$ and Uterine Infections. Uterine infections have been associated with both precalving and early lactation BCS loss (Butler and Smith, 1989; Markusfeld et al., 1997; Kim and Suh, 2003). In comparison, Waltner et al. (1993) failed to detect such a relationship. One Dutch (Heuer et al., 1999) and one German (Hoedemaker et al., 2009) study reported a greater risk of metritis (i.e., odds ratio of 1.9 and 2.95, respectively) in thin cows, and a recent study in New Zealand identified low postpartum BCS in younger cows (i.e., less than fourth lactation), with increased numbers of polymorphonuclear cells in uterine samples 28 and 42 DIM, but found no such relationships in older cows $(\mathrm{S}$. McDougall, Animal Health Centre, Morrinsville, New Zealand; unpublished data). Although, it is not easily possible to separate cause and effect (i.e., did cows with infections lose BCS through an infection-induced reduction in DMI or did the lower BCS or greater BCS loss predispose cows to uterine infections?), the timing of the BCS state and BCS change of interest (precalving or very early postcalving) indicates that low BCS scores or BCS loss are risk factors for uterine infections.

Implications. The lack of consensus on the association between BCS and dairy cow health is probably a result of differences in the diseases investigated or possibly in the method of diagnosis. Periparturient meta- 
bolic disorders appear to be associated with elevated periparturient BCS, probably a result of reduced DMI postcalving because of overconditioning. The association between BCS and the risk of infection (uterine or mammary) is parity dependent, and data indicate that younger cows (third parity or less) will benefit from greater calving BCS. Precalving and calving BCS does not appear to influence the risk of dystocia; however, further research is required on the association between periconception BCS and BCS change and the risk of subsequent dystocia.

\section{Other Traits of Interest}

BCS and Secondary Sex Ratio. Trivers and Willard (1973) hypothesized that in species in which reproductive success varies more among one sex than the other, mothers in better physiological condition would be advantaged by investing more heavily in the more variable sex. Similarly, mothers with limited resources would be advantaged by investing in the more reproductively stable sex, thereby ensuring a continuation of the genetic line. This hypothesis is appropriate for species with a small litter size and depends on 3 premises (Trivers and Willard, 1973; Cameron et al., 1999): 1) that the condition of the young at the end of the parental investment is correlated with the condition of the dam during parental investment, 2) that these differences in condition tend to endure into adulthood, and 3 ) that the adult will be differentially advantaged in reproductive success through slight advantages in condition.

This model predicts that dairy cows in good physiological condition are more likely to produce male offspring, because the theory suggests that a male in good condition at the end of the period of parental investment is expected to out-reproduce female siblings. In a review of the literature, Cameron (2004) reported significant support for the hypothesis in only $34 \%$ of cases tested, with $8.5 \%$ of studies reporting results contrary to the hypothesis (i.e., dams in poorer condition produced more male offspring). However, Cameron (2004) further concluded that much of this inconsistency was a result of different definitions of "maternal condition," and that when studies testing maternal BCS were isolated, support for the hypothesis increased to $74 \%$.

From an analysis of a database containing 76,607 BCS records from 3,209 lactations across 1,172 cows, Roche et al. (2006b) concluded that there was a linear relationship between the logit of the probability of a male calf and BCS change between calving and conception, the rate of BCS change over this period (BCS change divided by DIM), and BCS at the calving event immediately before conception. The birth of a bull calf was 1.85 times more likely in cows that lost no BCS from calving to conception compared with cows that lost 1 BCS unit from calving to conception. This increase in odds was equivalent to a 14-percentage-point increase in the probability of a male calf (from 52 to $66 \%$ ). Consistent with this, the amount of BW lost between calving and conception and the rate of loss affected the sex of the resultant offspring. Less BW loss or greater BW gain between calving and conception was associated with greater likelihood of a male calf. These findings have since been confirmed in horses (Cameron and Linklater, 2007) and humans (Mathews et al., 2008).

BCS and Epigenetics. Epigenetics is defined as nuclear inheritance that is not based on differences in DNA sequence (Holliday, 1984). It involves differential DNA methylation, histone acetylation, chromatin configuration, and other mechanisms, and is best exemplified by different tissues within an individual composed of cells expressing different proteins while having the same genetic makeup (Sinclair et al., 2007).

Increasing evidence exists for an effect of maternal nutrition in early pregnancy and throughout gestation on the physiology of the resultant offspring (Breier, 2006; Oliver et al., 2007; Sinclair et al., 2007; Berry et al., 2008a). The hypothesis is that a fetus becomes "programmed" to the uterine environment in which it finds itself, and this adaptation affects its ability to manage environmental stressors postparturition (Barker, 1995); Berry et al. (2008a) speculated that such programming may even occur preconception. The often-quoted example is that of the "thrifty phenotype," wherein an embryo/fetus exposed to a nutrient-sparse uterine environment is better able to adapt to a nutrient-sparse environment postparturition, but favorable postnatal conditions can challenge the individual's homeostatic mechanisms, leading to the development of deleterious metabolic conditions such as hypertension, dysfunction, dyslipidemia, and insulin resistance (Langley-Evans, 2006).

There is a growing body of evidence that periconception nutrition affects neonate size at birth (LangleyEvans, 2006), including in dairy cattle (Roche et al., 2006b). The main basis of the Barker hypothesis is that undernutrition in pregnancy impairs fetal growth or promotes disproportionate fetal growth and leads to altered physiological capacity in the long-term (LangleyEvans, 2006; Oliver et al., 2007; Sinclair et al., 2007). However, there are limited data available in dairy cows. As previously mentioned, Roche et al. (2006b) reported an altered secondary sex ratio and birth weight with differences in periconception BCS change, implying similar effects to those reported in other mammals. It was not possible, however, to determine the long-term 
consequences of these maternal periconception effects on milk production, reproduction, or several physiological processes involved in these functions (e.g., insulin resistance). Pryce et al. (2002) failed to detect any effect of maternal diet during gestation on heifer fertility, although this study was undertaken on only one farm where the difference in diet was not considerably large. However, Banos et al. (2007) reported that cows of greater BCS during gestation produced daughters with improved fertility, albeit with slightly reduced test-day milk yields. Similarly, Berry et al. (2008a) reported that survival and milk yield were reduced, and SCC was increased in the progeny of dams with greater milk yield preconception and during gestation, after accounting for the contribution of additive genetic effects on the traits under investigation. These imply that the extent of the negative energy balance during gestation may have trans-generational consequences on milk production, fertility, survival (possibly through reduced reproductive function), and immune function. Further research is required to quantify these effects and the mechanisms involved.

\section{BCS AND WELFARE}

Animal welfare is a social construct (Fisher, 2009). The concept of animal welfare differs between animals and circumstances (e.g., parity, weather, and animal genetics), people's perception of animal welfare (e.g., animal performance, feelings, or "natural" measures of welfare), and acceptable endpoint measurements (e.g., animal survival, performance, or comfort). There are many definitions, dimensions, and understandings of animal welfare (Duncan and Fraser, 1997; Nordenfelt, 2006; Fisher, 2009), but the most common reflect on how well an animal performs, what it feels, and that which is in keeping with the animal's nature.

\section{Performance and Animal Welfare}

When using performance as a measure, welfare is usually understood to be acceptable when animals grow or produce at a level acceptable for their genetics and environment, reproduce well, have normal physiology and behavioral functions, and live a relatively long life. Conversely, welfare is said to be reduced by disease, injury, and malnutrition.

In assessing the effects of BCS on animal welfare, it is clear that this biological understanding of animal welfare is predominant, as much of the information used in assessing welfare has been derived from the animal production literature. If this is indeed the way welfare is examined, extreme BCS (either too thin or too fat) reflects an increased risk of compromised animal wel- fare. As discussed previously, cows with either a low or a high BCS at calving tend to produce less milk, have impaired reproduction, and have reduced immune function (depending on parity), whereas thinness may increase the risk of discomfort in cold environments, and obesity may increase the risk of metabolic disorders.

Although many of the relationships described in the literature are significant, it is important to remember that they are often based on statistical associations, perhaps from a small number of animals or from records of herds containing a relatively small range of BCS. Furthermore, as Berry et al. (2007c) noted, the statistical significance of these relationships does not necessarily mean they are important biologically, especially in terms of individual animal welfare. However, it is also important to remember that commercially acceptable welfare standards based on herd productivity do not necessarily mean that individual animal welfare is optimal (Webster, 2005). Furthermore, selection for production can have undesirable side effects (Ott, 1996; Rauw et al., 1998; Sandøe et al., 1999). Arguably, undernutrition in dairy cows is a production disease, as selection for milk production shifts nutrients away from maintaining functional fitness (Wall et al., 2007).

\section{Feelings and Animal Welfare}

The second approach to defining welfare is that it is related to subjective feelings that animals experience (e.g., fear, frustration, pain, discomfort). Negative feelings are commonly regarded as suffering (Duncan, 2004). Feelings motivate the animal to react to needs (e.g., a need for food and water is associated with hunger and thirst, loneliness with a lack of social contact). Feelings and performance may be related (e.g., being and feeling ill reduces health and welfare, respectively). However, genetic selection and management of domestic animals can lead to situations where needs diverge from feelings, with well-fed and high-production animals experiencing hunger.

There are many examples where negative feelings, if severe or protracted, can lead to suffering. For example, fear, sickness, fatigue, anxiety, boredom, depression, nausea, sadness, anguish, paranoia, and torment all cause suffering (Gregory, 2004). Some high-yielding dairy cows may be motivated by hunger, a function of milk yield and low BCS, satiety associated with gut fill, inappetence associated with an unbalanced diet, or by the conflicting desire to do something other than eat, such as ruminate or rest. Of such a dairy cow, Webster (2005) states "her feelings may be defined, with brutal accuracy, as simultaneously hungry, tired, full up and feeling sick." Similarly, a Compassion in World Farming analysis of bST (D'Silva, 1998) suggested that a cow 


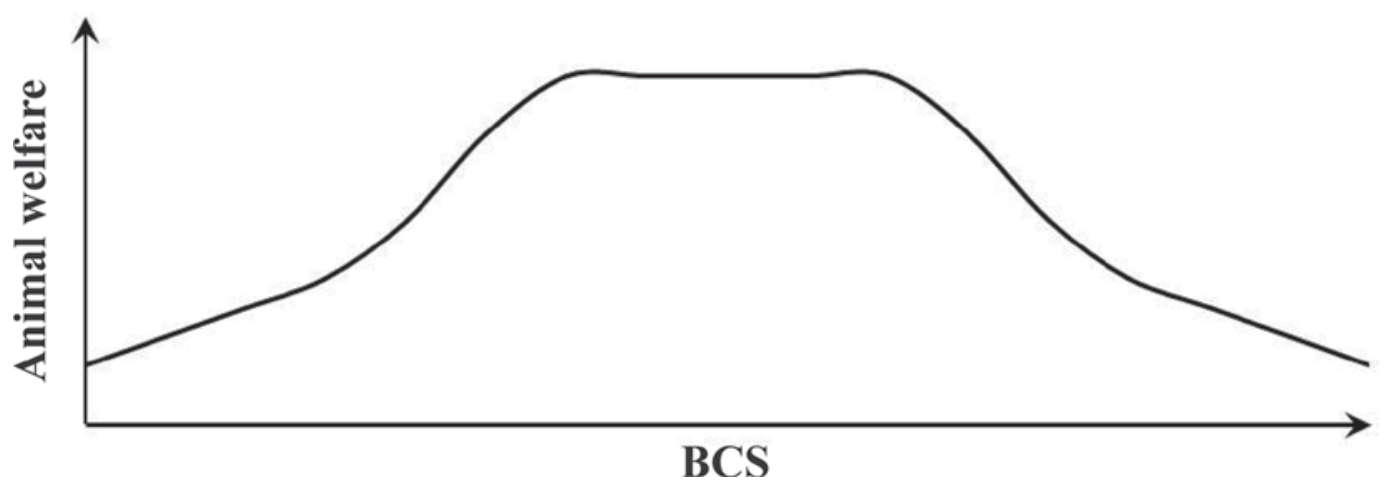

Figure 5. A stylized relationship between animal welfare and body condition score.

in negative energy balance will probably not be feeling "well."

Little is known about what dairy cows are feeling during lactation, especially during periods of negative energy balance, or how this may be associated with BCS. For example, do cows in excessive negative energy balance have to spend too much time feeding and ruminating at the expense of other activities?

The subjectivity of feelings makes them a challenge to describe and measure, but they can be evaluated. Animal behavior, preference and motivation testing, and the self-administration of analgesics to reduce pain have all been used in attempts to measure what animals are feeling (Duncan, 2004). The concept of pleasurable feelings reflecting good animal welfare also requires consideration. The contented cow may have value in counterbalancing the unavoidable, negative feelings or suffering that animals experience (Duncan, 2004). Despite the difficulties in assessing what a cow in low BCS or negative energy balance feels, it is suggested that it should be a focus of future research, especially in intensive grazing systems, which provide additional challenges related to climate and pasture availability and quality.

\section{Natural Animal Welfare}

A third, but less utilized understanding of animal welfare, at least within science, is that good welfare is synonymous with an animal's nature or telos, reflecting the needs and interests that cows have, and that matter to them, by virtue of their biology and psychology (Rollin, 2007). Thus, the belief is that animals should be kept in a "natural" environment and be allowed to behave "naturally" (Rollin, 1990; Duncan and Fraser, 1997). The modern dairy cow may not be a "natural" animal, as it produces large volumes of milk and its calf is removed shortly after birth. It could also be argued that the way in which the modern dairy cow is managed is not natural. It may be housed and fed with manufactured rations instead of grazing. Furthermore, in spring-calving herds, husbandry interventions provide dairy cows with unnaturally high planes of nutrition during winter, when food would be naturally in short supply, resulting in body reserves or good BCS at calving (Garnsworthy, 1988). Additionally, mammals generally have regulatory mechanisms reducing intake as reserves increase to prevent excessive fatness; selection for high production may have altered these mechanisms regulating appetite (Rauw et al., 1998).

Nevertheless, the modern dairy cow presumably still has many features of the ancestral cow, suggesting that it might be motivated to perform activities regarded as natural (e.g., grazing, resting and sleeping, investigative, social, sexual, and maternal behavior; Webster, 1987). It is not known how important these activities are, or if they are reflected in, or affected by, BCS and energy balance.

\section{The Complexity of Animal Welfare}

Although a cow's BCS and changes in BCS reflect its energy reserves and, possibly, its welfare state, it is important to remember that welfare is affected by a multitude of factors, many of which may interact. Consequently, while it is possible to envisage a simple profile of the relationship between BCS and animal welfare (Figure 5), it is likely that this profile will vary between seasons, animals, breeds and genetic strains, and management systems. In pastoral situations, especially, the relationship will be influenced by the quality and quantity of nutrition and the prevailing weather.

Some relationships may be reasonably clear, but apply only in specific circumstances (e.g., BCS at which an animal shivers under cold stress). Other relationships are likely to be more subtle. For example, Roche et al. (2007c) suggested that a 0.25 -unit increase in BCS at the postcalving nadir would increase pregnancy to first service by $3 \%$. 
An additional factor making it difficult to devise a simple relationship between BCS and animal welfare is the limited nature of much of the published data. Many experiments have low numbers and, thus, statistical power (although studies can be combined; e.g., López-Gatius et al. 2003), contrast only 2 or 3 BCS states, and often only investigate BCS within the "normal" range common in commercial herds (Berry et al., $2007 \mathrm{~b}$ ), most of which are likely to be in good condition (Roche et al., 2007a). Finally, there is generally a lack of detailed measures in large data sets, and an association between measured parameters does not necessarily imply they are causal.

It is also important to note that animal welfare is essentially about the individual animal, whereas experimental relationships are derived from populations of animals. For instance, if the herd-average calving BCS is 3 , what proportion of cows are $\leq \mathrm{BCS} 2$ or $\geq \mathrm{BCS} 4$, and what factors affect this distribution?

These features imply that there will be no clear or simple BCS at which welfare changes from being acceptable to unacceptable. What risks are regarded as reasonable and necessary is not a decision that can be based on science alone. It is a value judgment, increasingly requiring systematic and rational reflection in the public sphere (Lassen et al., 2006). The inclusion of an understanding of "natural-based" welfare is probably going to be crucial in this regard, at least until data are collated that can begin to describe what cows are feeling.

Although humans have a duty for the care of animals, in most environments (both farming and natural) animals have to cope with changing and variable conditions (e.g., weather, climate, food supply). In addition to ensuring that animals are genetically suited and acclimated, good animal husbandry means ensuring they have adequate reserves (e.g., good BCS) and resources (e.g., feed to gain BCS). Thus, a relationship between BCS and animal welfare (Figure 5) needs to recognize the animal as an individual, and that the suitable BCS range, from an animal welfare perspective, will vary with animal, herd, and environmental factors.

\section{BCS Assessment for Animal Welfare}

Body condition scoring can be used for research, farm management, and animal welfare regulatory reasons, each arguably requiring different rationales and levels of precision and consistency. Similarly, BCS may be considered as an absolute value, as changes during a season or during an animal's life, or, possibly, as longer term trends or changes within the dairy industry. In doing so, it is important to remember that BCS is a subjective measurement of the energy status of the animal, and thus an inferred risk to animal welfare, and that efforts to transform it into a more objective measurement may, like any risk analysis, obscure the complexity of factors it reflects and give a deceptive impression of its precision (Chalmers, 1990). For example, as discussed earlier in this review, Kristensen et al. (2006) reported significant variation in assessing BCS between 51 practicing veterinarians.

In conclusion, it is suggested that the welfare of some dairy cows is, at times, compromised by being in poor BCS. This is based on both the biological performance of the animal, and the likely, but yet to be scientifically established, belief that she may feel hungry, tired, full, or sick (Webster, 2005). "Using production measures to improve management is immediately relevant; attempting to discover how animals feel is forward thinking" (H. W. Gonyou, cited in Curtis, 2007). Both concepts of welfare are regarded as critical in the socio-political climate that ultimately determines acceptable animal welfare. On the one hand, there is a likely perception that good production indicates good welfare. However, increased production inevitably brings health and welfare risks requiring additional skills and expertise. On the other hand, we do not necessarily understand what the cow is feeling, although common sense would suggest that she experiences some discomfort. Clearly, BCS and animal welfare is a complex topic informed by factors as diverse as genetic merit, feeding, climate, and farming system, and the need for society to determine what welfare compromises are both reasonable and necessary. It cannot be reduced to ensuring that animals have freedom from hunger, but requires an understanding of the animal's biology and the farm's ecological system, along with human needs and expectations of the way animals should be treated (Fisher and Mellor, 2008).

\section{AUTOMATION AND THE POTENTIAL OF TIME-SERIES MEASUREMENTS OF BCS IN DECISION SUPPORT TOOLS}

Decision support relates to information systems, including knowledge-based systems, which help in making decisions. Key to the success of a decision support system is the routine availability of high-quality data. The proliferation of automation in the modern dairy herd for daily tasks, such as milking and estrus detection, means that large quantities of data, which can be incorporated into decision support software, are being routinely collected, and could be used to support dairy producers in making operational and tactical decisions on farm. Such approaches can be undertaken at both a herd level and an individual cow level. 
This review highlights that the subjective appraisal of an individual cow's BCS is a useful predictor of its energy status as well as its future risk of health or reproductive failure (and therefore animal welfare). Routine measures of BCS over time could further improve its predictive ability. Nevertheless, although body condition scoring is rapid, it requires an experienced person to undertake the task. In rapidly expanding herds without a concomitant increase in the amount of labor or husbandry skill, the commitment of skilled labor to undertake routine BCS assessment is not always possible.

Recent studies have reported that routine assessment of BCS can be undertaken with varying degrees of automation. Coffey et al. (2003) evaluated the potential of predicting BCS using structured red laser light shone on the tail head of a cow and captured with a digital camera positioned to be $45^{\circ}$ to the horizontal plane of the cow's back. For each of the red stripes on the digital image, 2 quadratic curves were fitted, one for the tail head and the other for either the left or right buttock. The correlation between tail head curvature and BCS was 0.55 and between right pin bone curvature and BCS was 0.59 . Therefore, 30 to $35 \%$ of the variation in BCS could be explained using this technique.

A further option could be to mount a digital camera (or a series of digital cameras positioned differently) in a race when cows are exiting the parlor. Photographs taken could be sent to a dairy herd advisor or to a central location, each animal assessed for BCS, and the results returned to the farmer via a decision support software package. Ferguson et al. (2006) reported strong correlations $(\geq 0.82)$ between BCS assessed live and that assessed from digital images with 4 operators. The accuracy obtained may be further augmented by using infrared light such as that used by Coffey (2003), to further emphasize the anatomy of the cow. Bewley et al. (2008) used a digital camera mounted 60 to $70 \mathrm{~cm}$ above a cow's back and pointing directly downward to photograph each cow; these photographs were subsequently used to identify the coordinates of 23 anatomical points that the researchers thought may be associated with BCS. Angles between coordinates were calculated to reflect the shape of the contours, and calculated angles that were significantly associated with BCS were used in the prediction model. They reported that $100 \%$ of the BCS values predicted by the model were within 0.50 points of actual BCS scored by a trained assessor, whereas $93 \%$ were within 0.25 points of actual BCS. However, these are likely to be upper thresholds, because the results reported were based on the data used in the calibration of the models and the model regression coefficients were not applied to an independent (validation) data set, as would be the case in reality.

Accuracy of the aforementioned approaches to predict BCS could possibly be improved by including other "nuisance" or correlated factors in the model such as parity of cow, DIM, and, if measured simultaneously, BW. Furthermore, taking account of the time-series of previous measurements from that cow may also improve accuracy of predicting BCS or BCS change. Although this has not yet been done for BCS it has been shown to be important for other automatically measured indicators (Norberg et al., 2008).

The data generated by the chosen approach can be stored on the farm database and preferably uploaded into a national database. Analyses of data in both databases can provide useful information for decision support. For example, routine within-herd statistical analysis of data on a given date can be used to compare animals within different contemporary groups (e.g., parity) and adjusted for nuisance variables (e.g., DIM). The availability of time-series BCS data makes it possible to derive cohort lactation curves (e.g., Roche et al., 2007a), and animals deviating from their respective cohort can be highlighted for preferential treatment. Using statistical approaches, such as random regression models with a covariance structure fitted among terms of the polynomial, or differential smoothing using extended Kalman filters on individual cows, BCS profiles of cows into the future may be predicted, thereby alerting, at an early stage, the producer to potential "problem cows" or cows requiring preferential treatment. Further, such data would then become available for incorporation into decision support systems that, for example, predict the risk of the cow developing ketosis or of having reproductive problems (Friggens and Chagunda, 2005; Nielsen et al., 2005) or the need to adjust nutrition recommendations (Tedeschi et al., 2006).

From a national perspective, the longitudinal BCS data can be used in genetic evaluations to generate EBV for BCS indicating whether animals have genes associated with high or low BCS. Availability of EBV for BCS can be useful in identifying suitable germplasm for breeding, which in turn can be incorporated into mating advice programs (i.e., a form of decision support). The availability of data generated from herds nationally, in one database, facilitates, through the use of statistical models, such as test-day models, the calculation of effects particular to a given herd on a given date, after adjusting for genetic effects and nuisance environmental effects. These solutions can be used by individual herds to evaluate recent changes in management. Furthermore, herd BCS lactation profiles may 


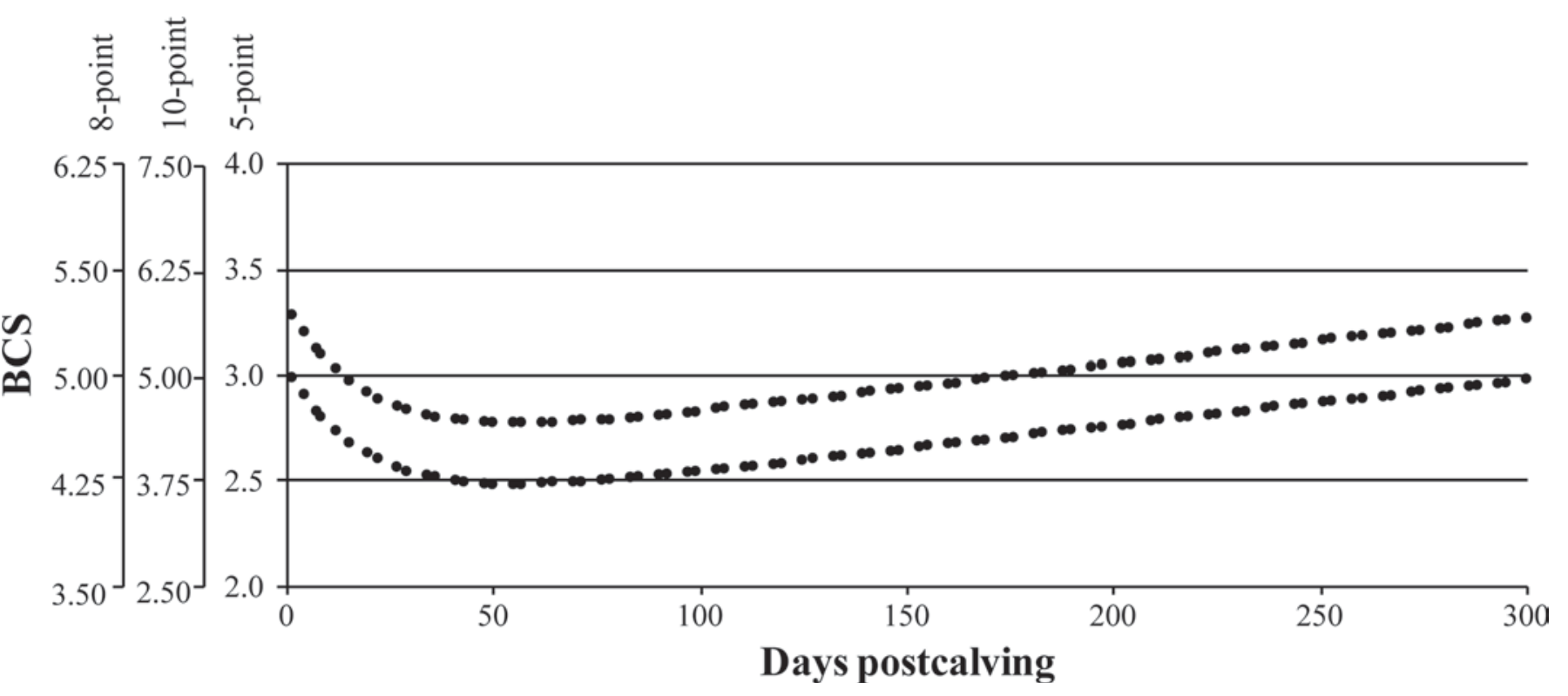

Figure 6. The range in acceptable profiles that allow cows to produce near maximum milk production for their genetics and production system, while ensuring reproduction, health, and animal welfare are not compromised. Body condition score is presented for the 5-, 8-, and 10-point scales. Adapted from Chagas et al. (2007).

be generated and can be compared with contemporary herds (e.g., similar sized farms in the same region). Availability of such reports would allow producers to benchmark their performance against contemporaries.

\section{CONCLUSIONS}

There is general recognition that BCS provides a gross but reasonably accurate measure of a cow's energy reserves, although its use is limited in very thin and very fat cows. Calving BCS is probably the most influential time point in the cow's lactation calendar, as it affects early lactation DMI, postcalving BCS loss, milk yield, cow immunity and, although it does not directly affect pregnancy rate, it does influence reproduction through its effect on nadir BCS and BCS loss.

The collated data indicate an optimal BCS profile (Figure 6) that allows near maximum milk production for the system in place and the genetic merit of the cow, while ensuring that reproduction, health and animal welfare are not compromised. Cows should calve between 3.0 and 3.25 (5-point; equivalent to 5.0 to 5.25 on an 8-point scale and 5.0 to 5.5 on a 10 -point scale). Cows that calve thinner than this produce less milk, likely have extended PPAI, are less likely to get pregnant, and are more likely to present themselves in an animal welfare-risk category. Cows that calve in greater BCS will have a reduced DMI, will produce less milk, and are more likely to succumb to periparturient metabolic disorders. Data indicate that management and nutrition in early lactation have little effect on
BCS loss, but increased dietary NSC results in greater post-nadir BCS gain. The review further highlights the need for preferential treatment for primiparous cows to ensure their trajectory of BCS gain post-nadir is sufficient to ensure calving BCS is attained at their second calving.

The intercalving profile of BCS change can be modeled using empirical and mechanistic techniques, with varying degrees of success. Combined with routine and automated recording of BCS on-farm, these models may be incorporated into decision support tools to predict future BCS profiles and, thus, performance, or alter management decisions.

Further research is required into the effect of BCS state and BCS change on animal health and welfare, as well as DMI, and the possibility of transgenerational epigenetic changes and associated effects on future production, health, and reproduction.

\section{ACKNOWLEDGMENTS}

The authors acknowledge the financial support of New Zealand dairy farmers, through DairyNZ Inc (Project No. AN803), and the Ministry of Agriculture and Forestry, New Zealand, through the Sustainable Farming Fund (Project No. 08/012).

\section{REFERENCES}

Ahima, R. S., and J. S. Flier. 2000. Leptin. Annu. Rev. Physiol. $62: 413-437$. 
Anderson, J. B., N. C. Friggens, T. Larsen, M. Vestergaard, and K. L. Ingvartsen. 2003. Effect of energy density in the diet and milking frequency on plasma metabolites and hormones in early lactation dairy cows. J. Vet. Med. A. 51:52-57.

Andrew, S. M., D. R. Waldo, and R. A. Erdman. 1994. Direct analysis of body composition of dairy cows at three physiological stages. J. Dairy Sci. 77:3022-3033.

Avramoglu, R. K., and K. Adeli. 2004. Hepatic regulation of apolipoprotein B. Rev. Endocr. Metab. Disord. 5:293-301.

Banos, G., S. Brotherstone, and M. P. Coffey. 2007. Prenatal maternal effects on body condition score, female fertility, and milk yield of dairy cows. J. Dairy Sci. 90:3490-3499.

Barker, D. J. P. 1995. Fetal origins of coronary heart disease. BMJ 311:171-174

Bauchart, D. 1993. Lipid absorption and transport in ruminants. J. Dairy Sci. 76:3864-3881.

Bauman, D. E. 1976. Intermediary metabolism of adipose tissue. Fed. Proc. 35:2308-2313

Bauman, D. E. 2000. Regulation of nutrient partitioning during lactation: Homeostasis and homeorhesis revisited. Pages 311-327 in Ruminant Physiology: Digestion, Metabolism and Growth and Reproduction. P. J. Cronje, ed. CAB Publishing, New York, NY.

Bauman, D. E., and W. B. Currie. 1980. Partitioning of nutrients during pregnancy and lactation: A review of mechanisms involving homeostasis and homeorhesis. J. Dairy Sci. 63:1514-1529.

Bauman, D. E., and C. L. Davis. 1974. Biosynthesis of Milk Fat. Pages 31-75 in Lactation: A Comprehensive Treatise, Vol. 2. B. L. Larson and V. R. Smith, ed. Academic Press, New York, NY.

Beam, S. W., and W. R. Butler. 1999. Effects of energy balance on follicular development and first ovulation in postpartum dairy cows. J. Reprod. Fertil. 54:411-424.

Bell, A. W. 1995. Regulation of organic nutrient metabolism during transition from late pregnancy to early lactation. J. Anim. Sci $73: 2804-2819$.

Bell, A. W., and D. E. Bauman. 1997. Adaptations of glucose metabolism during pregnancy and lactation. J. Mammary Gland Biol. Neoplasia 2:265-278.

Bernard, C. 1856. Memoir of the Pancreas. Academic Press, New York, NY.

Bernstein, I. L., E. C. Lotter, P. J. Kulkosky, D. Porte Jr., and S. C. Woods. 1975. Effect of force-feeding upon basal insulin levels of rats. Proc. Soc. Exp. Biol. Med. 150:546-548.

Berry, D. P., F. Buckley, and P. Dillon. 2007a. Body condition score and live-weight effects on milk production in Irish Holstein-Friesian dairy cows. Animal 1:1351-1359.

Berry, D. P., F. Buckley, P. Dillon, R. D. Evans, M. Rath, and R. F. Veerkamp. 2003a. Genetic relationships among body condition score, body weight, milk yield and fertility in dairy cows. J. Dairy Sci. 86:2193-2204.

Berry, D. P., F. Buckley, P. Dillon, R. D. Evans, M. Rath, and R. F. Veerkamp. 2003b. Genetic parameters for body condition score, body weight, milk yield, and fertility estimated using random regression models. J. Dairy Sci. 86:3704-3717.

Berry, D. P., F. Buckley, P. Dillon, R. D. Evans, M. Rath, and R. F. Veerkamp. 2003c. Genotype x environment interaction for milk yield, body condition score, and body weight in a grass based system using random regression models. Livest. Prod. Sci. 83:191-203.

Berry, D. P., F. Buckley, P. G. Dillon, R. D. Evans, M. Rath, and R. F. Veerkamp. 2002. Genetic parameters for level and change of body condition score and body weight in dairy cows. J. Dairy Sci. 85:2030-2039.

Berry, D. P., B. Horan, and P. G. Dillon. 2005. Comparison of growth curves of three strains of female dairy cattle. Anim. Sci. 80:151160.

Berry, D. P., J. M. Lee, K. A. Macdonald, and J. R. Roche. 2007b. Body condition score and body weight effects on dystocia and stillbirths and consequent effects on post-calving performance. J. Dairy Sci. 90:4201-4211.

Berry, D. P., J. M. Lee, K. A. Macdonald, K. Stafford, L. Matthews, and J. R. Roche. 2007c. Associations between body condition score, body weight, somatic cell count, and clinical mastitis in seasonally calving dairy cattle. J. Dairy Sci. 90:637-648.

Berry, D. P., P. Lonergan, S. T. Butler, A. R. Cromie, T. Fair, F. Mossa, and A. C. O. Evans. 2008a. Negative influence of high maternal milk production before and after conception on offspring survival and milk production in dairy cattle. J. Dairy Sci. 91:329337.

Berry, D. P., K. A. Macdonald, J. W. Penno, and J. R. Roche. 2006a. Association between body condition score and live weight in pasture-based Holstein-Friesian dairy cows. J. Dairy Res. 73:487491.

Berry, D. P., J. R. Roche, and M. P. Coffey. 2008b. Body condition score and fertility - more than just a feeling. Pages 107-118 in Fertility in Dairy Cows: Bridging the Gaps. M. D. Royal, N. C. Friggens, and R. F. Smith, ed. British Society of Animal Science, Cambridge University Press, Cambridge, UK.

Berry, D. P., R. F. Veerkamp, and P. Dillon. 2006b. Phenotypic profiles for body weight, body condition score, energy intake, and energy balance across different parities and concentrate feeding levels. Livest. Sci. 104:1-12.

Bewley, J. M., A. M. Peacock, O. Lewis, R. E. Boyce, D. J. Roberts, M. P. Coffey, S. J. Kenyon, and M. M. Schutz. 2008. Potential for estimation of body condition scores in dairy cattle from digital images. J. Dairy Sci. 91:3439-3453.

Bewley, J. M., and M. M. Schutz. 2008. Review: An interdisciplinary review of body condition scoring for dairy cattle. Prof. Anim. Sci 24:507-529.

Blache, D., S. Zhang, and G. B. Martin. 2006. Dynamic and integrative aspects of the regulation of reproduction by metabolic status in male sheep. Reprod. Nutr. Dev. 46:379-390.

Blanc, F., and J. Agabriel. 2008. Modelling the reproductive efficiency in a beef cow herd: Effect of calving date, bull exposure and body condition at calving on the calving-conception interval and calving distribution. J. Agric. Sci. 146:143-161.

Block, S. S., W. R. Butler, R. A. Ehrhardt, A. W. Bell, M. E. Van Amburgh, and Y. R. Boisclair. 2001. Decreased concentration of plasma leptin in periparturient dairy cows is caused by negative energy balance. J. Endocrinol. 171:339-348.

Bourchier, C. P., P. C. Garnsworthy, J. M. Hutchinson, and T. A. Benton. 1987. The relationship between milk yield, body condition and reproductive performance in high yielding dairy cows. Anim. Prod. 44:460. (Abstr.)

Breier, B. H. 2006. Prenatal nutrition, fetal programming and opportunities for farm animal research. Pages 347-361 in Ruminant Physiology: Digestion, Metabolism and Impact of Nutrition on Gene Expression, Immunology and Stress. K. Sejrsen, T. Hvelplund, M. O. Nielsen, ed. Wageningen Academic Publishers, Wageningen, the Netherlands.

Breier, B. H., P. D. Gluckman, and J. J. Bass. 1988. The somatotrophic axis in young steers: Influence of nutritional status and oestradiol$17 \beta$ on hepatic high- and low-affinity somatotrophic binding sites. J. Endocrinol. 116:169-177.

Brindle, N. P., V. A. Zammit, and C. I. Pogson. 1985. Regulation of carnitine palmitoyltransferase activity by malonyl CoA in mitochondria from sheep liver, a tissue with low capacity for fatty acid synthesis. Biochem. J. 232:177-182.

Britt, J. H. 1991. Impacts of early postpartum metabolism on follicular development and fertility. Bovine Pract. Proc. 24:39-43.

Broster, W. H., and V. J. Broster. 1998. Body score of dairy cows. J. Dairy Res. 65:155-173.

Bryant, J. R., N. Lopez-Villalobos, C. W. Holmes, J. E. Pryce, G. D. Pitman, and S. R. Davis. 2007. The effect of level of feeding, genetic merit, body condition score and age on biological parameters of a mammary gland model. Animal 1:175-183.

Buckley, F., K. O'Sullivan, J. F. Mee, R. D. Evans, and P. Dillon 2003. Relationships among milk yield, body condition, cow weight, and reproduction in spring-calved Holstein-Friesians. J. Dairy Sci. $86: 2308-2319$

Butler, W. R., and R. D. Smith. 1989. Interrelationships between energy balance and postpartum reproductive function in dairy cattle. J. Dairy Sci. 72:767-783. 
Caldeira, R. M., A. T. Belo, C. C. Santos, M. I. Vazques, and A. V. Portugal. 2007. The effect of body condition score on blood metabolites and hormonal profiles in ewes. Small Rumin. Res. 68:233-241.

Cameron, E. Z. 2004. Facultative adjustment of mammalian sex ratios in support of the Trivers-Willard hypothesis: Evidence for a mechanism. Proc. R. Soc. Lond. B Biol. Sci. 271:1723-1728.

Cameron, E. Z., and W. L. Linklater. 2007. Extreme sex ratio variation in relation to change in condition around conception. Biol. Lett. 3:395-397.

Cameron, E. Z., W. L. Linklater, K. J. Stafford, and C. J. Veltman. 1999. Birth sex ratios relate to mare condition at conception in Kaimanawa horses. Behav. Ecol. 10:472-475.

Chagas, L. M., J. J. Bass, D. Blache, C. R. Burke, J. K. Kay, D. R. Lindsay, M. C. Lucy, G. B. Martin, S. Meier, F. M. Rhodes, J. R. Roche, W. W. Thatcher, and R. Webb. 2007. Invited review: New perspectives on the roles of nutrition and metabolic priorities in the subfertility of high-producing dairy cows. J. Dairy Sci. 90:4022-4032.

Chagas, L. M., M. C. Lucy, P. J. Back, D. Blache, J. M. Lee, P. J. S. Gore, A. J. Sheahan, and J. R. Roche. 2009. Insulin resistance in divergent strains of Holstein-Friesian dairy cows offered fresh pasture and increasing amounts of concentrate in early lactation. J. Dairy Sci. 92:216-222.

Chalmers, A. 1990. Science and its Fabrication. Open University Press, Milton Keynes, UK

Chassagne, M., J. Barnouin, and J. P. Chaconac. 1999. Risk factors for stillbirth in Holstein heifers under field conditions in France: A prospective study. Theriogenology 51:1477-1488.

Chihara, K., N. Minamitani, H. Kaji, A. Arimura, and T. Fujita. 1981. Intraventricularly injected growth hormone stimulates somatostatin release into rat hypophysial portal blood. Endocrinology 109:2279-2281.

Chilliard, Y. 1986. Variations quantitative et metabolism des lipids dans les tissus adipeux et le foie au cours du cycle gestation-lactation. 1ere partie: Chez la ratte. Reprod. Nutr. Dev. 26:1057-1103.

Chilliard, Y., C. Delavaud, and M. Bonnet. 2005. Leptin expression in ruminants: Nutritional and physiological regulations in relation with energy metabolism. Domest. Anim. Endocrinol. 29:3-22.

Chilliard, Y., A. Ferlay, Y. Faulconnier, M. Bonnet, J. Rouel, and F. Bocquier. 2000. Adipose tissue metabolism and its role in adaptations to undernutrition in ruminants. Proc. Nutr. Soc. 59:127-134.

Chomczynski, P., T. R. Downs, and L. A. Frohman. 1988. Feedback regulation of growth hormone $(\mathrm{GH})$-releasing hormone gene expression by GH in rat hypothalamus. Mol. Endocrinol. 2:236241.

Coffey, M. P. 2003. A phenotypic and genetic analysis of energy balance in dairy cows. PhD Dissertation. University of Edinburgh, Edinburgh, UK.

Coffey, M. P., N. McFarlane, and T. Mottram. 2003. The feasibility of automatic condition scoring. Holstein J. 66:82-83.

Coffey, M. P., G. Simm, and S. Brotherstone. 2002. Energy balance profiles for the first three lactations of dairy cows estimated using random regression models. J. Dairy Sci. 85:2669-2678.

Coffey, M. P., G. Simm, J. D. Oldham, W. G. Hill, and S. Brotherstone. 2004. Genotype and diet effects on energy balance in the first three lactations of dairy cows. J. Dairy Sci. 87:4318-4326.

Collard, B. L., P. J. Boettcher, J. C. M. Dekkers, D. Petitclerc, and L. R. Schaeffer. 2000. Relationship between energy balance and health traits of dairy cattle in early lactation. J. Dairy Sci. 83:2683-2690.

Considine, R. V. 2001. Regulation of leptin production. Rev. Endocr. Metab. Disord. 2:357-363.

Cummings, D. E., and K. E. Foster. 2003. Ghrelin-leptin tango in body-weight regulation. Gastroenterology 124:1532-1535.

Curtis, S. E. 2007. Performance indicates animal state of being: A Cinderella axiom? Prof. Anim. Sci. 23:573-583.

D'Silva, J. 1998. BST - A distressing product. An analysis of the health and welfare problems of dairy cows injected with BST. Compassion in World Farming Report. http://www.ciwf.org.uk/publications/ reports/bst_a_distressing_product_1998.pdf Accessed March 13, 2008.

Darwin, C. 1859 On the Origin of Species by Means of Natural Selection, or the Preservation of Favoured Races in the Struggle for Life. J. Murray, London, UK.

Davies, D. T., C. Holt, and W. W. Christie. 1983. The composition of milk. Pages 71-117 in Biochemistry of Lactation. T. P. Mepham, ed. Elsevier, New York, NY.

Dechow, C. D., G. W. Rogers, and J. S. Clay. 2001. Heritabilities and correlations among body condition scores, production traits, and reproductive performance. J. Dairy Sci. 84:266-275.

Dechow, C. D., G. W. Rogers, and J. S. Clay. 2002. Heritability and correlations among body condition score loss, body condition score, production and reproductive performance. J. Dairy Sci. 85:3062-3070.

Dechow, C. D., G. W. Rogers, L. Klei, and T. J. Lawlor. 2004 Heritability and correlations for body condition score and dairy form within and across lactation and age. J. Dairy Sci. 87:717728

DEFRA. 2001. Condition scoring of dairy cows. Publication PB6492. Department for Environment, Food and Rural Affairs, London, UK.

del Rincon, J. P., K. Iida, B. D. Gaylinn, C. E. McCurdy, J. W Leitner, L. A. Barbour, J. J. Kopchick, J. E. Friedman, B. Draznin, and M. O. Thorner. 2007. Growth hormone regulation of p85 alpha expression and phosphoinositide 3-kinase activity in adipose tissue: mechanism for growth hormone-mediated insulin resistance. Diabetes 56:1638-1646.

Delaby, L., P. Faverdin, G. Michel, C. Disenhaus, and J. L. Peyraud. 2009. Effect of different feeding strategies on lactation performance of Holstein and Normande dairy cows. Animal 3:891-905.

Dillon, P. 2006. A comparison of different dairy cow breeds on a seasonal grass-based system of milk production. 2. Reproduction and survival. Livest. Prod. Sci. 83:35-42.

Diskin, M. G., D. R. Mackey, J. F. Roche, and J. M. Sreenan. 2003. Effects of nutrition and metabolic status on circulating hormones and ovarian follicle development in cattle. Anim. Reprod. Sci. $78: 345-370$

DNRE. 2002. The Condition Magician. Body condition scoring in dairy herds. Department of Natural Resources and Environment, Victoria, Australia.

Doeschl-Wilson, A. B., P. W. Knap, B. P. Kinghorn, and H. A. M. Van der Steen. 2007. Using mechanistic animal growth models to estimate genetic parameters of biological traits. Animal 1:489499

Domecq, J. J., A. L. Skidmore, J. W. Lloyd, and J. B. Kaneene. 1997a. Relationship between body condition scores and milk yield in a large dairy herd of high yielding Holstein cows. J. Dairy Sci. 80:101-112.

Domecq, J. J., A. L. Skidmore, J. W. Lloyd, and J. B. Kaneene. 1997b. Relationship between body condition scores and conception at first artificial insemination in a large dairy herd of high yielding Holstein cows. J. Dairy Sci. 80:113-120.

Drackley, J. K. 1999. Biology of dairy cows during the transition period: the final frontier. J. Dairy Sci. 82:2259-2273.

Drackley, J. K. 2009. Influence of metabolic disorders on reproductive performance in dairy and veal. 1. Etiological and diagnostic aspects. Large Anim. Rev. 15:37-40.

Drackley, J. K., T. R. Overton, and G. N. Douglas. 2001. Adaptations of glucose and long-chain fatty acid metabolism in liver of dairy cows during the periparturient period. J. Dairy Sci. 84(E Suppl.):E100-E112.

Duffield, T. 2000. Subclinical ketosis in lactating dairy cattle. Vet. Clin. North Am. Food Anim. Pract. 16:231-253.

Duncan, I. J. H. 2004. A concept of welfare based on feelings. Pages 85101 in The Well-Being of Farm Animals. Challenges and Solutions. G. J. Benson and B. E. Rollin, ed. Blackwell, Ames, IA.

Duncan, I. J. H., and D. Fraser. 1997. Understanding animal welfare. Pages 19-31 in Animal Welfare. M. C. Appleby and B. O. Hughes, ed. CABI Publishing, Wallingford, UK. 
Dyk, P. B. 1995. The association of prepartum non-esterified fatty acids and body condition with peripartum health problems of 95 Michigan dairy farms. MS Thesis. Michigan State Univ., East Lansing.

Earle, D. F. 1976. A guide to scoring dairy cow condition. J. Agric. (Victoria) 74:228-231.

Edmonson, A. J., I. J. Lean, L. D. Weaver, T. Farver, and G. Webster. 1989. A body condition scoring chart for Holstein dairy cows. J. Dairy Sci. 72:68-78.

Ellis, J. L., F. Qiao, and J. P. Cant. 2006. Evaluation of net energy expenditures of dairy cows according to body weight changes over a full lactation. J. Dairy Sci. 89:1546-1557.

Enevoldsen, C., and T. Kristensen. 1997. Estimation of body weight from body size measurements and body condition scores in dairy cows. J. Dairy Sci. 80:1988-1995.

Etherton, T. D., and D. E. Bauman. 1998. Biology of somatotropin in growth and lactation of domestic animals. Physiol. Rev. 78:745761.

Ettema, J. F., and J. E. P. Santos. 2004. Impact of age at calving on lactation, reproduction, health, and income in first-parity Holsteins on commercial farms. J. Dairy Sci. 87:2730-2742.

Ferguson, J. D., G. Azzaro, and G. Licitra. 2006. Body condition using digital images. J. Dairy Sci. 89:3833-3841.

Ferguson, J. D., D. T. Galligan, and N. Thomsen. 1994. Principal descriptors of body condition score in Holstein cows. J. Dairy Sci. $77: 2695-2703$

Fielding, B. A., and K. N. Frayn. 1998. Lipoprotein lipase and the disposition of dietary fatty acids. Br. J. Nutr. 80:495-502.

Fisher, M. W. 2009. Defining animal welfare - does consistency matter? N. Z. Vet. J. 57:71-73.

Fisher, M. W., and D. J. Mellor. 2008. Developing a systematic strategy incorporating ethical, animal welfare and practical principles to guide the genetic improvement of dairy cattle. N. Z . Vet. J. 56:100-106.

Fontaneli, R. S., L. E. Sollenberger, R. C. Littell, and C. R. Staples. 2005. Performance of lactating dairy cows managed on pasturebased or in freestall barn-feeding systems. J. Dairy Sci. 88:12641276.

Friggens, N. C. 2003. Body lipid reserves and the reproductive cycle: Towards a better understanding. Livest. Prod. Sci. 83:219-226.

Friggens, N. C., J. B. Andersen, T. Larsen, O. Aaes, and R. J. Dewhurst. 2004a. Priming the dairy cow for lactation: a review of dry cow feeding strategies. Anim. Res. 53:453-473.

Friggens, N. C., and J. H. Badsberg. 2007. The effect of breed and parity on lactation curves of body condition estimated using a non-linear function. Animal 1:565-574.

Friggens, N. C., P. Berg, P. Theilgaard, I. R. Korsgaard, K. L Ingvartsen, P. L. Løvendahl, and J. Jensen. 2007. Breed and parity effects on energy balance profiles through lactation: evidence for genetically driven body reserve change. J. Dairy Sci. 90:52915305

Friggens, N. C., and M. G. G. Chagunda. 2005. Prediction of the reproductive status of cattle on the basis of milk progesterone measures: Model description. Theriogenology 64:155-190.

Friggens, N. C., G. C. Emmans, I. Kyriazakis, J. D. Oldham, and M. Lewis. 1998. Feed intake relative to stage of lactation for dairy cows consuming total mixed diets with a high or low ration of concentrate to forage. J. Dairy Sci. 81:2228-2239.

Friggens, N. C., K. L. Ingvartsen, and G. C. Emmans. 2004b. Prediction of body lipid change in pregnancy and lactation. J. Dairy Sci. 87:988-1000.

Gagliostro, G., and Y. Chilliard. 1991. Duodenal rapeseed oil infusion in early and midlactation cows. 2. Voluntary intake, milk production, and composition. J. Dairy Sci. 74:499-509.

Gallo, L., P. Carnier, M. Cassandro, R. Dal Zotto, and G. Bittante. 2001. Test-day genetic analysis of condition score and heart girth in Holstein-Friesian cows. J. Dairy Sci. 84:2321-2326.

Gallo, L., P. Carnier, M. Cassandro, R. Mantovani, L. Bailoni, B Contiero, and G. Bittante. 1996. Change in body condition score of Holstein cows as affected by parity and mature equivalent milk yield. J. Dairy Sci. 79:1009-1015.
Garnsworthy, P. C. 1988. The effect of energy reserves at calving on performance of dairy cows. Pages $157-170$ in Nutrition and Lactation in the Dairy Cow. P. C. Garnsworthy, ed. Butterworths, London, UK.

Garnsworthy, P. C. 2006. Body condition score in dairy cows: Targets for production and fertility. Pages 61-86 in Recent Advances in Animal Nutrition. P. C. Garnsworthy and J. Wiseman, ed. Nottingham University Press, Nottingham, UK

Garnsworthy, P. C., and G. P. Jones. 1987. The influence of body condition at calving and dietary protein supply on voluntary food intake and performance in dairy cows. Anim. Prod. 44:347-353.

Garnsworthy, P. C., and J. H. Topps. 1982. The effect of body condition of dairy cows at calving on their food intake and performance when given complete diets. Anim. Prod. 35:113-119.

Gearhart, M. A., C. R. Curtis, H. N. Erb, R. D. Smith, C. J. Sniffen, L. E. Chase, and M. D. Cooper. 1990. Relationship of changes in condition score to cow health in Holsteins. J. Dairy Sci. 73:3132 3140 .

Gibb, M. J., W. E. Irvings, M. S. Dhanoa, and J. D. Sutton. 1992. Changes in body components of autumn-calving Holstein Friesian cows over the first 29 weeks of lactation. Anim. Prod. 5:339360.

Gillund, P., O. Reksen, Y. T. Grohn, and K. Karlberg. 2001. Body condition related to ketosis and reproductive performance in Norwegian dairy cows. J. Dairy Sci. 84:1390-1396.

Grainger, C., and A. A. McGowan. 1982. The significance of precalving nutrition of the dairy cow. Pages 134-171 in Proc. Conf. Dairy Production from Pasture. K. L. Macmillan and V. K. Taufa, ed. Clark and Matheson Ltd., Hamilton, New Zealand.

Grainger, C., G. D. Wilhelms, and A. A. McGowan. 1982. Effect of body condition at calving and level of feeding in early lactation on milk production of dairy cows. Aust. J. Exp. Agric. Anim. Husb. 22:9-17.

Gregory, N. G. 2004. Physiology and Behaviour of Animal Suffering. Blackwell Science, Oxford, UK

Grummer, R. R., P. C. Hoffman, M. L. Luck, and S. J. Bertics. 1995 Effect of prepartum and postpartum dietary energy on growth and lactation of primiparous cows. J. Dairy Sci. 78:172-180.

Herdt, T. H. 2000. Ruminant adaptation to negative energy balance: Influences on the etiology of ketosis and fatty liver. Vet. Clin. North Am. Food Anim. Pract. 16:215-230.

Heuer, C., Y. H. Schukken, and P. Dobbelaar. 1999. Postpartum body condition score and results from first test day milk as predictors of disease, fertility, yield, and culling in commercial dairy herds. J. Dairy Sci. 82:295-304.

Hoedemaker, M., D. Prange, and Y. Gundelach. 2009. Body condition change ante- and postpartum, health and reproductive performance in German Holstein cows. Reprod. Domest. Anim. 44:167-173.

Holliday, R. 1984. The significance of DNA methylation in cellular aging. Pages 269-283 in Molecular Biology of Aging. A. D. Woodhead, A. D. Blackett and A. Hollaender, ed. Plenum, New York, NY.

Houseknecht, K. L., C. P. Portocarrero, S. Ji, R. Lemenager, and M. E. Spurlock. 2000. Growth hormone regulates leptin gene expression in bovine adipose tissue: Correlation with adipose IGF1 expression. J. Endocrinol. 164:51-57.

Ingvartsen, K. L. 2006. Feeding- and management-related disease in the transition cow: Physiological adaptation around calving and strategies to reduce feeding-related diseases. Anim. Feed Sci. Technol. 126:175-213.

Ingvartsen, K. L., and J. B. Andersen. 2000. Integration of metabolism and intake regulation: A review focusing on periparturient animals. J. Dairy Sci. 83:1573-1597.

Ingvartsen, K. L., R. J. Dewhurst, and N. C. Friggens. 2003. On the relationship between lactational performance and health: Is it yield or metabolic imbalance that cause production diseases in dairy cattle? A position paper. Livest. Prod. Sci. 83:277-308.

Jesse, B. W.. R. S. Emery, and J. W. Thomas. 1986. Control of bovine hepatic fatty acid oxidation. J. Dairy Sci. 69:2298-2303. 
Johanson, J. M., and P. J. Berger. 2003. Birth weight as a predictor of calving ease and perinatal mortality in Holstein cattle. J. Dairy Sci. 86:3745-3755.

Kamon, J., T. Yamauchi, S. Muto, S. Takekawa, Y. Ito, Y. Hada, W. Ogawa, A. Itai, M. Kasuga, K. Tobe, and T. Kadowaki. 2004. A novel IKKbeta inhibitor stimulates adiponectin levels and ameliorates obesity-linked insulin resistance. Biochem. Biophys. Res. Commun. 323:242-248.

Katakami, H., T. R. Downs, and L. A. Frohman. 1987. Effect of hypophysectomy on hypothalamic growth hormone-releasing factor content and release in the rat. Endocrinology 120:1079-1082.

Kay, J. K., C. V. C. Phyn, J. R. Roche, and E. S. Kolver. 2009. Extending lactation in pasture-based dairy cows II: Effect of genetic strain and diet on plasma hormone and metabolite concentrations. J. Dairy Sci. 92:3704-3713.

Kennedy, G. C. 1953. The role of depot fat in the hypothalamic control of food intake in the rat. Proc. R. Soc. Lond. B Biol. Sci. 140:578 592.

Kim, I. H., and G. H. Suh. 2003. Effect of the amount of body condition loss from the dry to near calving periods on the subsequent body condition change, occurrence of postpartum diseases, metabolic parameters and reproductive performance in Holstein dairy cows. Theriogenology 60:1445-1456.

Knight, C. H. 2001. Lactation and gestation in dairy cows: Flexibility avoids nutritional extremes. Proc. Nutr. Soc. 60:527-537.

Koenen, E. P. C., R. F. Veerkamp, P. Dobbelaar, and G. De Jong. 2001. Genetic analysis of body condition score of lactating Dutch Holstein and Red-and-White heifers. J. Dairy Sci. 84:1265-1270.

Kolver, E. S., and L. D. Muller. 1998. Performance and nutrient intake of high producing holstein cows consuming pasture or a total mixed ration. J. Dairy Sci. 81:1403-1411.

Kolver, E. S., J. R. Roche, M. J. de Veth, P. L. Thorne, and A. R. Napper. 2002. Total mixed rations versus pasture diets: evidence for a genotype $\mathrm{x}$ diet interaction in dairy cow performance. Proc. N.Z. Soc. Anim. Prod. 62:246-251.

Kristensen, E., L. Dueholm, D. Vink, J. E. Andersen, E. B. Jakobsen, S. Illum-Nielsen, F. A. Petersen, and C. Enevoldsen. 2006. Withinand across-person uniformity of body condition scoring in Danish Holstein cattle. J. Dairy Sci. 89:3721-3728.

Lacetera, N., D. Scalia, U. Bernabucci, B. Ronchi, D. Pirazzi, and A. Nardone. 2005. Lymphocyte functions in overconditioned cows around parturition. J. Dairy Sci. 88:2010-2016.

Land, C., and J. D. Leaver. 1981. The effect of body condition at calving on the production of Friesian cows and heifers. Anim. Prod. 32:362-363. (Abstr.)

Langley-Evans, S. C. 2006. Development programming of health and disease. Proc. Nutr. Soc. 65:97-105.

Lassen, J., M. Gjerris, and P. Sandøe. 2006. After Dolly-Ethical limits to the use of biotechnology on farm animals. Theriogenology 65:992-1004

Lehner, R., and A. Kuksis. 1996. Biosynthesis of triacylglycerols. Prog. Lipid Res. 35:169-201.

Leury, B. J., L. H. Baumgard, S. S. Block, N. Segoale, R. A. Ehrhardt, R. P. Rhoads, D. E. Bauman, A. W. Bell, and Y. R. Boisclair. 2003. Effect of insulin and growth hormone on plasma leptin in periparturient dairy cows. Am. J. Physiol. Regul. Integr. Comp. Physiol. 285:R1107-R1115.

Liesman, J. S., J. P. McNamara, A. V. Capuco, M. Binelli, W. K. Vanderkool, R. S. Emery, H. A. Tucker, and W. M. Moseley. 1995. Comparison of growth hormone-releasing factor and somatotropin: Lipid and glucose metabolism in dairy cows. J. Dairy Sci. 78:2159-2166.

López-Gatius, F., J. Yániz, and D. Madriles-Helm. 2003. Effects of body condition score and score change on the reproductive performance of dairy cows: A meta-analysis. Theriogenology 59:801-812.

Lowman, B. G., N. Scott, and S. Somerville. 1973. Condition scoring of cattle. East of Scotland College of Agriculture, Bulletin No. 6, Edinburgh, UK.

Lucy, M. C., H. Jiang, and Y. Kobayashi. 2001. Changes in the somatotropin axis associated with the initiation of lactation. J. Dairy Sci. 84(E Suppl.):E113-E119.
Lucy, M. C., G. A. Verkerk, B. E. Whyte, K. A. Macdonald, L. Burton, R. T. Cursons, J. R. Roche, and C. W. Holmes. 2009. Somatotropic axis components and nutrient partitioning in genetically diverse dairy cows managed under different feed allowances in a pasture system. J. Dairy Sci. 92:526-539.

Macdonald, K. A., and J. R. Roche. 2004. Condition Scoring Made Easy. Condition Scoring Dairy Herds. 1st ed. Dexcel Ltd., Hamilton, New Zealand.

Macdonald, K. A., G. A. Verkerk, B. S. Thorrold, J. E. Pryce, J. W. Penno, L. R. McNaughton, L. J. Burton, J. A. S. Lancaster, J. H. Williamson, and C. W. Holmes. 2008. A comparison of three strains of Holstein-Friesian grazed on pasture and managed under different feed allowances. J. Dairy Sci. 91:1693-1707.

Markusfeld, O. 1985. Relationship between overfeeding, metritis and ketosis in high yielding dairy cows. Vet. Rec. 116:489-491.

Markusfeld, O., N. Gallon, and E. Ezra. 1997. Body condition score, health, yield and fertility in dairy cows. Vet. Rec. 141:67-72.

Martin, O., and D. Sauvant. 2009. Modelling homeorhetic drive and homeostatic control of dairy cow energy metabolism. J. Theor. Biol. In press.

Mathews, F., P. J. Johnson, and A. Neil. 2008. You are what your mother eats: Evidence for maternal preconception diet influencing foetal sex in humans. Proc. Biol. Sci. 275:1661-1668.

Mayo, K. E., P. A. Godfrey, S. T. Suhr, D. J. Kulik, and J. O. Rahal. 1995. Growth hormone-releasing hormone: synthesis and signaling. Recent Prog. Horm. Res. 50:35-73.

McCann, J. P., E. N. Bergman, and D. H. Beermann. 1992. Dynamic and static phases of severe dietary obesity in sheep: food intakes, endocrinology and carcass and organ chemical composition. J. Nutr. 122:496-505.

McCarthy, S., D. P. Berry, P. Dillon, M. Rath, and B. Horan. 2007. Influence of Holstein-Friesian strain and feed system on bodyweight and body condition score lactation profiles. J. Dairy Sci. 90:18591869 .

McGarry, J. D., and N. F. Brown. 1997. The mitochondrial carnitine palmitoyltransferase system. From concept to molecular analysis. Eur. J. Biochem. 244:1-14.

McNamara, J. P. 1988. Regulation of bovine adipose tissue metabolism during lactation. 4. Dose responsiveness to epinephrine as altered by stage of lactation. J. Dairy Sci. 71:643-649.

McNamara, J. P. 1989. Regulation of bovine adipose tissue metabolism during lactation. 5. Relationships of lipid synthesis and lipolysis with energy intake and utilization. J. Dairy Sci. 72:407-418.

McNamara, J. P. 1991. Regulation of adipose tissue metabolism in support of lactation. J. Dairy Sci. 74:706-719.

McNamara, J. P. 2004. Research, improvement and application of mechanistic, biochemical, dynamic models of metabolism in lactating dairy cows. Anim. Feed Sci. Technol. 112:155-176.

McNamara, J. P., and R. L. Baldwin. 2000. Estimation of parameters describing lipid metabolism in lactation: Challenge of existing knowledge described in a model of metabolism. J. Dairy Sci. 83:128-143.

McNamara, J. P., and J. K. Hillers. 1986a. Regulation of bovine adipose tissue metabolism during lactation. 1. Lipid synthesis in response to increased milk production and decreased energy intake. J. Dairy Sci. 69:3032-3041.

McNamara, J. P., and J. K. Hillers. 1986b. Regulation of bovine adipose tissue metabolism during lactation. 2. Lipolyysis response to milk production and energy intake. J. Dairy Sci. 69:3042-3050.

Meijering, A. 1984. Dystocia and stillbirth in cattle - A review of causes, relations and implications. Livest. Prod. Sci. 11:143-177.

Meyer, C. L., P. J. Berger, K. J. Koehler, J. R. Thompson, and C. G. Sattler. 2001. Phenotypic trends in incidence of stillbirth for Holsteins in the United States. J. Dairy Sci. 84:515-523.

Miglior, F., B. L. Muir, and B. J. Van Doormaal. 2005. Selection indices in Holstein cattle of various countries. J. Dairy Sci. $88: 1255-1263$.

Minami, S., J. Kamagai, H. Sugihara, N. Suzuki, and I. Wakabayashi. 1998. Growth hormone inhibits its own secretion by acting on the hypothalamus through its receptors on neuropeptide Y neurons in 
the arcuate nucleus and somatostatin neurons in the periventricular nucleus. Endocrinol. Jpn. 45(Suppl.):S19-S26.

Misztal, I. 2006. Properties of random regression models using linear splines. J. Anim. Breed. Genet. 123:74-80.

Mitchel, J. S., and R. E. Keesey. 1977. Defence of a lowered weight maintenance level by lateral hypothalmically lesioned rats: evidence from a restriction-refeeding regimen. Physiol. Behav. 18:1121-1125.

Monod, F. 1970. Le hazard et la necessité. Le Seuil, Paris, France.

Mulvaney, P. 1977. Dairy cow condition scoring. Handout No. 4468. National Institute for Research in Dairying. Reading, UK.

Murray, J. A. 1919. Meat production. J. Agric. Sci. Camb. 9:174181.

Nielsen, N. I., N. C. Friggens, M. G. G. Chagunda, and K. L. Ingvartsen. 2005. Predicting the risk of ketosis in dairy cows using on-line measurements of beta-hydroxybutyrate in milk: A biological model. J. Dairy Sci. 88:2441-2453.

Norberg, E., I. R. Korsgaard, K. H. M. N. Sloth, and P. Løvendahl. 2008. Time-series models on somatic cell score improve detection of mastitis. Acta Agric. Scand. A 58:165-169.

Nordenfelt, L. 2006. Animal and human health and welfare: A comparative philosophical analysis. CABI, Wallingford, UK.

NRC. 2001. Energy. Pages 13-27 in Nutrient Requirements of Dairy Cattle. 7th rev. ed. Natl. Acad. Sci., Washington, DC.

Okada, T., Y. Kawano, T. Sakakibara, O. Hazeki, and M. Ui. 1994. Essential role of phosphatidylinositol 3-kinase in insulin-induced glucose transport and antilipolysis in rat adipocytes: studies with a selective inhibitor wortmannin. J. Biol. Chem. 269:3568-3573.

Oliver, M. H., A. L. Jaquiery, F. H. Bloomfield, and J. E. Harding. 2007. The effects of maternal nutrition around the time of conception on the health of the offspring. Pp 397-410 in Reproduction in Domesticated Ruminants, Nottingham University Press, UK.

Oltenacu, P. A., and I. Ekesbo. 1994. Epidemiological study of clinical mastitis in dairy cattle. Vet. Res. 25:208-217.

Ott, R. S. 1996. Animal selection and breeding techniques that create diseased populations and compromise welfare. J. Am. Vet. Med. Assoc. 208:1969-1974.

Otto, K. L., J. D. Ferguson, D. G. Fox, and C. J. Sniffen. 1991. Relationship between body condition score and composition of ninth to eleventh rib tissue in Holstein dairy cows. J. Dairy Sci. 74:852-859.

Pedernera, M., S. C. García, A. Horagadoga, I. Barchia, and W. J. Fulkerson. 2008. Energy balance and reproduction on dairy cows fed to achieve low or high milk production on a pasture-based system. J. Dairy Sci. 91:3896-3907.

Peeler, E. J., M. J. Otte, and R. J. Esslemont. 1994. Inter-relationships of periparturient diseases in dairy cows. Vet. Rec. 134:129-132.

Petruzzi, H., A. Danfær, and N. C. Friggens. 2004. A dynamic model of feed intake regulation in dairy cows. Model evaluation. J. Anim. Feed Sci. 13:25-49.

Pond, C. M. 1984. Pages 1-29 in Physiological Strategies in Lactation. M. Peaker, R. G. Vernon, and C. H. Knight, ed. The Zoological Society of London, London, UK.

Pryce, J. E., M. P. Coffey, S. H. Brotherstone, and J. A. Woolliams. 2002. Genetic relationships between calving interval and body condition score conditional on milk yield. J. Dairy Sci. 85:15901595.

Pryce, J. E., M. P. Coffey, and G. Simm. 2001. The relationship between body condition score and reproductive performance. J. Dairy Sci. 84:1508-1515.

Pryce, J. E., and B. L. Harris. 2006. Genetics of body condition score in New Zealand dairy cows. J. Dairy Sci. 89:4424-4432.

Radcliff, R. P., B. L. McCormack, B. A. Crooker, and M. C. Lucy. 2003. Growth hormone (GH) binding and expression of $\mathrm{GH}$ receptor $1 \mathrm{~A}$ mRNA in hepatic tissue of periparturient dairy cows. J. Dairy Sci. 86:3933-3940.

Rauw, W. M., E. Kanis, E. N. Noordhuizen-Stassen, and F. J. Grommers. 1998. Undesirable side effects of selection for high production efficiency in farm animals: A review. Livest. Prod. Sci. $56: 15-33$.
Reksen, O., Ø. Havrevoll, Y. T. Grohn, T. Bolstad, A. Waldmann, and E. Ropstad. 2002. Relationships among body condition score, milk constituents, and postpartum luteal function in Norwegian dairy cows. J. Dairy Sci. 85:1406-1415.

Rhoads, R. P., J. W. Kim, B. J. Leury, L. H. Baumgard, N. Segoale, S. J. Frank, D. E. Bauman, and Y. R. Bosclair. 2004. Insulin increases the abundance of the growth hormone receptor in liver and adipose tissue of periparturient dairy cows. J. Nutr. 134:1020-1027.

Roche, J. R. 2007. Milk production responses to pre- and post-calving dry matter intake in grazing dairy cows. Livest. Sci. 110:12-24.

Roche, J. R., and D. P. Berry. 2006. Periparturient climatic, animal, and management factors influencing the incidence of milk fever in grazing systems. J. Dairy Sci. 89:2775-2783.

Roche, J. R., D. P. Berry, and E. S. Kolver. 2006a. Holstein-Friesian strain and feed effects on milk production, body weight, and body condition score profiles in grazing dairy cows. J. Dairy Sci. 89:3532-3543.

Roche, J. R., D. P. Berry, J. M. Lee, K. A. Macdonald, and R. C. Boston. 2007a. Describing the body condition score change between successive calvings: A novel strategy generalizable to diverse cohorts. J. Dairy Sci. 90:4378-4396.

Roche, J. R., D. Blache, J. K. Kay, D. R. Miller, A. J. Sheahan, and D. W. Miller. 2008. Neuroendocrine and physiological regulation of intake, with particular reference to domesticated ruminant animals. Nutr. Res. Rev. 21:207-234.

Roche, J. R., C. R. Burke, J. K. Kay, C. V. C. Phyn, S. Meier, and M. C. Lucy. 2009c. Genetic strain x diet interactions on physiological parameters associated with milk production, energy partitioning, and reproduction. Proc. Int. Symp. Rum. Nutr. In press.

Roche, J. R., P. G. Dillon, C. R. Stockdale, L. H. Baumgard, and M. J. VanBaale. 2004. Relationships among international body condition scoring systems. J. Dairy Sci. 87:3076-3079.

Roche, J. R., E. S. Kolver, and J. K. Kay. 2005. Influence of precalving feed allowance on periparturient metabolic and hormonal responses and milk production in grazing dairy cows. J. Dairy Sci. 88:677689.

Roche, J. R., J. M. Lee, and D. P. Berry. 2006b. Pre-conception energy balance and secondary sex ratio-Partial support for the TriversWillard hypothesis in dairy cows. J. Dairy Sci. 89:2119-2125.

Roche, J. R., J. M. Lee, K. A. Macdonald, and D. P. Berry. 2007b. Relationships among body condition score, body weight, and milk production variables in pasture-based dairy cows. J. Dairy Sci. 90:3802-3815.

Roche, J. R., K. A. Macdonald, C. R. Burke, J. M. Lee, and D. P. Berry. 2007c. Associations among body condition score, body weight, and reproductive performance in seasonal-calving dairy cattle. J. Dairy Sci. 90:376-391.

Roche, J. R., L. R. Turner, J. M. Lee, D. C. Edmeades, D. J. Donaghy, K. A. Macdonald, J. W. Penno, and D. P. Berry. 2009a. Weather, herbage quality and milk production in pastoral systems. 2 . Temporal patterns and intra-relationships in herbage quality and mineral concentration parameters. Anim. Prod. Sci. 49:200-210.

Roche, J. R., L. R. Turner, J. M. Lee, D. C. Edmeades, D. J. Donaghy, K. A. Macdonald, J. W. Penno, and D. P. Berry. 2009b. Weather, herbage quality and milk production in pastoral systems. 4. Effects on dairy cattle production. Anim. Prod. Sci. 49:222-232.

Rogers, K. V., L. Vician, R. A. Steiner, and D. K. Clifton. 1988. The effect of hypophysectomy and growth hormone administration on pre-prosomatostatin messenger ribonucleic acid in the periventricular nucleus of the rat hypothalamus. Endocrinology 122:586-591.

Rollin, B. E. 1990. Animal welfare, animal rights and agriculture. J. Anim. Sci. 68:3456-3461.

Rollin, B. E. 2007. Cultural variation, animal welfare and telos. Anim. Welf. 16(Suppl. 1):129-133.

Ruegg, P. L., and R. L. Milton. 1995. Body condition scores of Holstein cows on Prince Edward island: Relationships with yield, reproductive performance, and disease. J. Dairy Sci. 78:552-564.

Ruppert, L. D., J. K. Drackley, D. R. Bremmer, and J. H. Clark. 2003. Effects of tallow in diets based on corn silage or alfalfa silage on 
digestion and nutrient use by lactating dairy cows. J. Dairy Sci. 86:593-609.

Sandøe, P., B. L. Nielsen, L. G. Christensen, and P. Sørensen. 1999. Staying good while playing God - the ethics of breeding farm animals. Anim. Welf. 8:313-328.

Sinclair, K. D., R. G. Lea, W. D. Rees, and L. E. Young. 2007. The developmental origins of health and disease: current theories and epigenetic mechanisms. Pp 425-433 in Reproduction in Domesticated Ruminants, Nottingham University Press, UK.

Singh, I. 1997. Biochemistry of peroxisomes in health and disease. Mol. Cell. Biochem. 167:1-29.

Smith, T. R., and J. P. McNamara. 1990. Regulation of bovine adipose tissue metabolism during lactation. 6. Cellularity and hormonesensitive lipase activity as affected by genetic merit and energy intake. J. Dairy Sci. 73:772-783.

Steinbock, L., A. Nasholm, B. Berglund, K. Johansson, and J. Philipsson. 2003. Genetic effects of stillbirth and calving difficulty in Swedish Holsteins at first and second calving. J. Dairy Sci. $86: 2228-2235$.

Stipanuk, M. H. 2000. Biochemical and Physiological Aspects of Human Nutrition. W. B. Saunders, Pennsylvania, PA.

Stockdale, C. R. 2001. Body condition at calving and the performance of dairy cows in early lactation under Australian conditions: A review. Aust. J. Exp. Agric. 41:823-829.

Stockdale, C. R. 2004a. Effects of level of feeding of concentrates during early lactation on the yield and composition of milk from grazing dairy cows with varying body condition score at calving. Aust. J. Exp. Agric. 44:1-9.

Stockdale, C. R. 2004b. Effects of feeding magnesium sulfate to dry pregnant dairy cows with different body condition scores on intake in late gestation, periparturient blood calcium concentrations and production in early lactation. Aust. J. Exp. Agric. 44:539-546.

Stockdale, C. R. 2005. Investigating the interaction between body condition at calving and pre-calving energy and protein nutrition on the early lactation performance of dairy cows. Aust. J. Exp. Agric. 45:1507-1518.

Sumner, J. M., and J. P. McNamara. 2007. Expression of lipolytic genes in the adipose tissue of pregnant and lactating Holstein dairy cattle. J. Dairy Sci. 90:5237-5246.

Suriyasathaporn, W., M. Nielen, S. J. Dieleman, A. Brand, E. N. Noordhuizen-Stassen, and Y. H. Schukken. 1998. Use of Cox proportional-hazards model with time-dependent covariates to evaluate the relationship between body-condition score and the risks of first insemination and pregnancy in a high-producing dairy herd. Prev. Vet. Med. 37:159-172.

Tedeschi, L. O., W. Chapula, E. Janczewski, D. G. Fox, C. J. Sniffen, R. Munson, P. J. Kononoff, and R. Boston. 2008. Evaluation and application of the CPM dairy nutrition model. J. Agric. Sci. Camb. 146:171-182.

Tedeschi, L. O., S. Seo, D. G. Fox, and R. Ruiz. 2006. Accounting for energy and protein reserve changes in predicting diet-allowable milk production in cattle. J. Dairy Sci. 89:4795-4807.

Theilgaard, P., N. C. Friggens, K. H. Sloth, and K. L. Ingvartsen. 2002. The effect of breed, parity and body fatness on the lipolytic response of dairy cows. Anim. Sci. 75:209-219.

Thompson, J. R., E. J. Pollak, and C. L. Pelissier. 1983. Interrelationships of parturition problems, production of subsequent lactation, reproduction, and age at first calving. J. Dairy Sci. 66:11191127.

Tolkamp, B. J., G. C. Emmans, and I. Kyriazakis. 2006. Body fatness affects feed intake of sheep at a given body weight. J. Anim. Sci. 84:1778-1789.

Treacher, R. J., I. M. Reid, and C. J. Roberts. 1986. Effect of body condition at calving on the health and performance of dairy cows. Anim. Prod. 43:1-6.

Trivers, R. L., and D. Willard. 1973. Natural selection of parental ability to vary the sex ratio of offspring. Science 179:90-92.
Uribe, H. A., B. W. Kennedy, S. W. Martin, and D. F. Kelton. 1995. Genetic parameters for common health disorders of Holstein cows. J. Dairy Sci. 78:421-430.

Van Arendonk, J. A. M., G. J. Nieuwhof, H. Vos, and S. Korver. 1991. Genetic aspects of feed intake and efficiency in lactating dairy heifers. Livest. Prod. Sci. 29:263-275.

van Knegsel, A. T. M., H. van den Branda, J. Dijkstra, S. Tamminga, and B. Kemp. 2005. Effect of dietary energy source on energy balance, production, metabolic disorders and reproduction in lactating dairy cattle. Reprod. Nutr. Dev. 45:665-688.

Veerkamp, R. F., C. L. M. Gerritsen, E. P. C. Koenen, A. Hamoen, and G. De Jong. 2002. Evaluation of classifiers that score linear type traits and body condition score using common sires. J. Dairy Sci. 85:976-983.

Vernon, R. G. 1992. Control of lipogenesis and lipolysis. Pages 59-82 in The Control of Fat and Lean Deposition. P. J. Buttery, K. N. Boorman, and D. B. Lindsay, ed. Butterworth-Heinemann, London, UK.

Vernon, R. G., and C. M. Pond. 1997. Adaptations of maternal adipose tissue to lactation. J. Mammary Gland Biol. Neoplasia $2: 231-241$.

Waddington, C. H. 1957. The Strategy of the Genes. A Discussion of Some Aspects of Theoretical Biology. 1st ed. George Allen \& Unwin Ltd., London, UK.

Wall, E., M. P. Coffey, and S. Brotherstone. 2007. The relationship between body energy traits and production and fitness traits in first-lactation dairy cows. J. Dairy Sci. 90:1527-1537.

Walsh, S., F. Buckley, K. Pierce, N. Byrne, J. Patton, and P. Dillon. 2008. Effects of breed and feeding system on milk production, body weight, body condition score, reproductive performance, and postpartum ovarian function. J. Dairy Sci. 91:4401-4413.

Waltner, S. S., J. P. McNamara, and J. K. Hillers. 1993. Relationships of body condition score to production variables in high producing Holstein dairy cows. J. Dairy Sci. 76:3410-3419.

Waltner, S. S., J. P. McNamara, J. K. Hillers, and D. L. Brown. 1994. Validation of indirect measures of body fat in lactating cows. J. Dairy Sci. 77:2570-2579.

Washburn, S. P., S. L. White, J. T. Green Jr., and G. A. Benson. 2002. Reproduction, mastitis, and body condition of seasonally calved Holstein and Jersey cows in confinement or pasture systems. J. Dairy Sci. 85:105-111.

Wathes, D. C., M. Fenwick, Z. Cheng, N. Bourne, S. Llewellyn, D. G. Morris, D. Kenny, J. Murphy, and R. Fitzpatrick. 2007. Influence of negative energy balance on cyclicity and fertility in the high producing dairy cow. Theriogenology 68S:S232-S241.

Webster, J. 1987. Understanding the Dairy Cow. BSP Professional Books, London, UK

Webster, J. 2005. Animal Welfare: Limping Towards Eden. Blackwell, Oxford, UK.

Wildman, E. E., G. M. Jones, P. E. Wagner, R. L. Boman, H. F. Troutt Jr., and T. N. Lesch. 1982. A dairy cow body condition scoring system and its relationship to selected production characteristics. J. Dairy Sci. 65:495-501.

Wilmink, J. B. M. 1987. Adjustment of lactation yield for age at calving in relation to level of production. Livest. Prod. Sci. 16:321-334.

Wright, I. A., and A. J. F. Russel. 1984. Partition of fat, body composition and body condition score in mature cows. Anim. Prod. 38:23-32.

Yeaman, S. J. 2004. Hormone-sensitive lipase - New roles for an old enzyme. Biochem. J. 379:11-22.

Zhang, Y., R. Proenca, M. Maffei, M. Barone, L. Leopold, and J. M. Friedman. 1994. Positional cloning of the mouse obese gene and its human homologue. Nature 372:425-432.

Zieba, D. A., M. Amstalden, and G. L. Williams. 2005. Regulatory roles of leptin in reproduction and metabolism: A comparative review. Domest. Anim. Endocrinol. 29:166-185. 